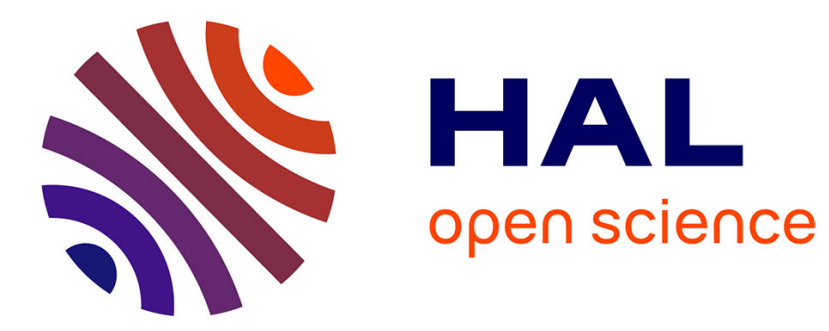

\title{
Effect of carbon nanofibers on the cure kinetics of unsaturated polyester resin: thermal and chemorheological modelling
}

Marco Monti, Debora Puglia, Maurizio Natali, Luigi Torre, José M. Kenny

\section{- To cite this version:}

Marco Monti, Debora Puglia, Maurizio Natali, Luigi Torre, José M. Kenny. Effect of carbon nanofibers on the cure kinetics of unsaturated polyester resin: thermal and chemorheological modelling. Composites Science and Technology, 2011, 10.1016/j.compscitech.2011.06.010 . hal-00786581

\section{HAL Id: hal-00786581 \\ https://hal.science/hal-00786581}

Submitted on 9 Feb 2013

HAL is a multi-disciplinary open access archive for the deposit and dissemination of scientific research documents, whether they are published or not. The documents may come from teaching and research institutions in France or abroad, or from public or private research centers.
L'archive ouverte pluridisciplinaire HAL, est destinée au dépôt et à la diffusion de documents scientifiques de niveau recherche, publiés ou non, émanant des établissements d'enseignement et de recherche français ou étrangers, des laboratoires publics ou privés. 


\section{Accepted Manuscript}

Effect of carbon nanofibers on the cure kinetics of unsaturated polyester resin: thermal and chemorheological modelling

Marco Monti, Debora Puglia, Maurizio Natali, Luigi Torre, José M. Kenny

PII: S0266-3538(11)00216-8

DOI: 10.1016/j.compscitech.2011.06.010

Reference: CSTE 5010

To appear in:

Composites Science and Technology

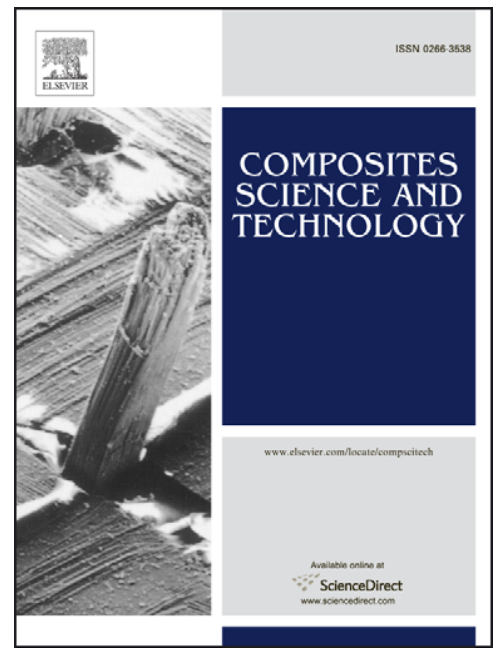

Received Date: $\quad 11$ January 2011

Revised Date: $\quad 17$ June 2011

Accepted Date: 19 June 2011

Please cite this article as: Monti, M., Puglia, D., Natali, M., Torre, L., Kenny, J.M., Effect of carbon nanofibers on the cure kinetics of unsaturated polyester resin: thermal and chemorheological modelling, Composites Science and Technology (2011), doi: 10.1016/j.compscitech.2011.06.010

This is a PDF file of an unedited manuscript that has been accepted for publication. As a service to our customers we are providing this early version of the manuscript. The manuscript will undergo copyediting, typesetting, and review of the resulting proof before it is published in its final form. Please note that during the production process errors may be discovered which could affect the content, and all legal disclaimers that apply to the journal pertain. 


\section{Effect of carbon nanofibers on the cure kinetics of unsaturated}

\section{polyester resin: thermal and chemorheological modelling}

Marco Monti ${ }^{1}$, Debora Puglia ${ }^{\mathbf{1}^{*}}$, Maurizio Natali ${ }^{1}$, Luigi Torre ${ }^{\mathbf{1}}$, José M. Kenny ${ }^{\mathbf{1 , 2}}$

${ }^{\mathbf{1}}$ University of Perugia, Civil and Environmental Engineering Department, UdR

INSTM, Strada di Pentima 4, 05100 Terni, Italy

${ }^{2}$ Institute of Polymer Science and Technology - CSIC - Juan de la Cierva 3, 28006

Madrid, Spain

*Corresponding author: dpuglia@unipg.it, Tel. +390744492916, Fax +390744492934

\section{Abstract}

We report the study of the effects of carbon nanofibers (CNFs) on the cure kinetics and on the chemorheology of unsaturated polyester resins (UP). Two main experimental techniques were utilized: differential scanning calorimetry and rheometry. Isothermal and dynamic tests were performed on the neat polyester resin and on two nanocomposite systems, with 0.5 and $1.0 \mathrm{wt} \%$ of CNFs. Furthermore, a TGA study of the selected systems at different isothermal temperatures was performed to evaluate the styrene consumption and related loss rate during the curing process. Subsequently, a phenomenological model (autocatalytic approach) was applied to the experimental data, both in isothermal and dynamic conditions. In the case of dynamic curing, the evidence of multiple peaks in the heat flow curves was studied through the deconvolution of the overall reaction thermogram in single reaction steps. An empirical rheological model coupled with the reaction kinetics was successfully applied to simulate the viscosity changes of the UP matrix. Experimental and modelling results demonstrate the presence of a delay effect of the CNFs on the cure of the UP resin matrix.

Keywords: A. Nano composites, B. Curing, D. Differential scanning calorimetry (DSC), D. Rheology, cure kinetics. 


\section{Introduction}

The cure reaction of thermosetting resins is particularly relevant due to the wide use of these polymers in a large number of industrial processes and applications. Thorough knowledge of the dynamics of the chemical reactions involved in the curing of thermosets can lead to the optimization of their processes in terms of processing time, costs and final properties of the materials produced. Moreover, following the important role of thermosetting polymers as matrices of composites and nanocomposites, this topic acquires particular relevance due to the complex chemorheological effects of the interaction of the matrices with the reinforcing phase. While the modelling of the chemorheological behaviour of thermosetting polymers and matrices of composite materials has been extensively reported in scientific literature [1-3], the same does not apply to nanocomposites. In this sense, the modelling of cure kinetics is important because it represents a very powerful tool in analyzing how the introduction of nanocomposite matrices in traditional fiber composites can affect the processing condition and curing time. In fact, if the cure reaction is delayed by the presence of nanoparticles, it represents additional efforts and costs for processing optimization in large-scale production.

Of all the thermosetting polymers, unsaturated polyester resins play an important role because of their versatility in properties, flexibility in processing and low cost.

Therefore, the kinetics and monitoring of an UP resin cure have been intensively studied in the last twenty-five years [1-7]. The cure reaction of UP resins follows a free radical reaction mechanism, which is quite complex, involving initiation, propagation and termination. Due to the rapid build-up of a crosslinked network, copolymerization leads to the early formation of microgels, even at conversion levels as low as 3-4\% [13]. Another parameter to take into account is the use of styrene as solvent and reactive material, which is normally subjected to evaporation, being a highly volatile component 
of the reactive system. In fact, a significant loss of styrene can occur during processing when the resin is still completely liquid, as well as during the exothermic polymerization.

Since the discovery of the great potential for breakthrough properties that nano-sized particles have on polymers, the interest in thermoset curing shifted to the study of the role of nanoparticles in the cure reaction of thermoset-based nanocomposites. Many researchers have paid attention to this topic, demonstrating that no simple and univocal cure behaviour trend can be encountered when nanoparticles are mixed with a thermoset [8-11]. In particular, most of the studies were performed on epoxy systems, whereas according to our investigation, less attention has been focused on polyester-based nanocomposites. In particular, some studies have focused on the effects of the introduction of nanoclays [12-17] and POSS [18-19] on the curing kinetics of UP nanocomposites. In particular, Zhou et al. [17] found a delaying effect of modified montmorillonite nanoplatelets on the curing reaction of polyester matrices.

Very limited information is instead available on the effect of carbon-based nanofillers on the cure reaction of UP resins, although the employment of this kind of fillers in an UP matrix has great potential on modifying the electrical, thermal and mechanical behaviour of the unfilled systems [20-31].

Among the different techniques which can be used to study the cure kinetics of a thermosetting polymer [32-35], DSC and rheometry are two of the main approaches commonly employed. Differential scanning calorimetry (DSC) is based on the assumption that the heat produced during cure is proportional to the extent of reaction. Although it gives little or no information on the chemistry associated to the reaction, it is one of the most popular techniques for cure monitoring because of its simplicity and relative rapidity. Chemorheology follows the curing process by monitoring the viscoelastic behaviour of the reacting systems, which is directly related to the change in 
molecular weight from the liquid state to an infinite molecular network (gelation) and eventually to a glassy state (vitrification).

In this research, the two aforementioned approaches are used to study the cure process of an UP resin filled with vapour-grown carbon nanofibers. Then, a phenomenological model is used to obtain the kinetic parameters of the cure process adopting a mathematical approach previously proposed for fibre reinforced UP matrices [3]. The kinetic model is then combined with an empirical rheological model proposed by Castro and Macosko for polyurethane systems [36] and successfully applied to describe the chemorheology of unsaturated polyester systems by Kenny and coworkers [3].

\section{Material and Methods}

The resin employed in this study was a low-viscosity ortophtalic unsaturated polyester resin supplied by Cray Valley, its commercial name being Enydyne I 68835 (41\% styrene content, see table 1). Carbon nanofibers, produced by Grupo Antolìn (Spain) and named GANF, were employed as a nanofiller. GANFs are helical ribbon carbon nanofibers, which consist of a continuous graphene sheet rolled up along the fiber axis [37]. As claimed by the manufacturer, they have very small diameters $(20-80 \mathrm{~nm})$, high aspect ratio (>100) and highly graphitic structure (graphitization degree about $70 \%$ ). They are provided without any chemical functionalization. For this study, they were employed as supplied by the manufacturer, with two different contents, namely 0.5 and $1 \mathrm{wt} \%$.

The dispersion process of the CNFs inside the polyester resin consisted of several steps. The accurately selected ratios of CNF:resin (0.5:99.5 and 1.0:99.0) were weighed and put in a vial which was connected to a high-shear mechanical stirrer. The vial was hermetically sealed, in order to hamper the strong styrene evaporation which is favoured by the heating of the mixture. This is due to the high shear stresses produced by the mixing itself, and causes a significant chemical change to the global reactive system and 
a change in the ratio of the resin to nanofibers. After 30 minutes of mechanical stirring the nanocomposite mixture was placed in an ultrasound bath for 1 hour to improve the homogeneity of the dispersion and to degas the mixture.

After the mixing procedure, the styrene content of the nanocomposite blends was evaluated, making it possible to calculate the amount of styrene evaporated during mechanical stirring. This calculation consisted of several steps (UNI EN ISO 3251). The nanocomposite mixture was diluted with acetone in a ratio of $1 \mathrm{mg}$ mixture to $3 \mathrm{ml}$ acetone and evenly dissolved. The obtained blend was put in an oven at $110^{\circ} \mathrm{C}$ for one hour and then removed, allowed to cool down to room temperature and weighed. The residual mass consisted of the polyester monomer and the carbon nanofibers (when present), whereas the lost part of the mass consisted of styrene and acetone. In this way, the styrene content of the mixture after the process can be easily calculated by the following equation:

$$
\%_{\text {styrene }}=\left(1-\frac{m_{2}-m_{C N F}}{m_{1}-m_{C N F}}\right) \cdot 100
$$

where $m_{2}$ is the residual mass after baking, $m_{1}$ is the initial mass of the nanocomposite mixture and $m_{\mathrm{CNF}}$ is the amount of CNFs in the weighed mixture, as calculated by $m_{\mathrm{CNF}}$ $=m_{1} *\left[\%_{\mathrm{CNFs}} /\left(100-\%_{\mathrm{CNFs}}\right)\right]$.

The styrene content in the neat resin as supplied by the manufacturer was also evaluated and compared with the content in the nanocomposite mixtures in order to calculate the exact amount of styrene needed for the same amount of styrene in the neat resin and in the nanocomposite blends. The styrene added has a purity which is more than $99 \%$ and was purchased from Sigma Aldrich. It was mixed with the blends by means of magnetic stirring for 1 hour. During this mixing phase, the vessel with the blends was sealed in order to avoid further styrene evaporation. After this process, the styrene content was evaluated again, to verify that the new styrene content was the same as the pristine resin. 
The cure reaction of the resin was activated by means of butanone peroxide, supplied by Sigma Aldrich, at the recommended percentage of $1.5 \mathrm{wt} \%$, and accelerated by $0.15 \mathrm{wt}$ $\%$ of cobalt octoate $(6 \%)$. The accelerator, cobalt octoate, was added before the mixing process, while the initiator was added just before the preparation of the specimens for testing. Both the peroxide and the cobalt octoate weight were considered part of the resin when establishing the ratio of the resin to CNF, that is the ratio CNF:UP was actually CNF:(UP+Peroxide+Co).

DSC tests were performed with a DSC Mettler Toledo, model 822e, and rheology tests with an ARES N2 Rheometric Scientific rheometer. Isothermal and dynamic scans were performed at various temperatures and scan rates for both DSC and rheology measurements. In particular, the isothermal tests were performed at $25-40-55^{\circ} \mathrm{C}$, and the dynamic tests were performed at $3-5-10^{\circ} \mathrm{C} / \mathrm{min}$. In all cases, the cure reaction occurred during testing, and the changes in heat flow and viscosity with time were monitored. Rheological tests were conducted with the parallel plate geometry (plate diameter $25 \mathrm{~mm}$ ) with a gap of about $1 \mathrm{~mm}$. They were performed in dynamic mode, setting the strain at $0.15 \%$, and with an oscillation frequency of $1 \mathrm{~Hz}$. In this study the viscosity was studied only at a single frequency because the dependence on the frequency was already investigated [20] and it was not part of this paper. Each test was repeated at least five times in order to minimize errors.

In a further analysis, we monitored the loss of weight of the three reactive systems in order to study the evaporation of volatile components during network formation. To achieve this, a Seiko model Exstar 6300 thermogravimetric analyzer was utilized. The tested isothermal curing temperatures were the same as in the other techniques (i.e. 25$\left.40-55^{\circ} \mathrm{C}\right)$. 
A morphological investigation on the blends was carried out by means of microscopy.

In particular, an optical microscope (Nikon Epiphot 300 reflection microscope) was employed to study the homogeneity of the dispersion in the liquid state, whereas a transmission electron microscope (Philips EM 208 TEM) was used for the investigation of the dispersion in the fully cured materials. Although optical microscopy can not give highly magnified images to observe single nanofibers and therefore to thoroughly investigate the degree of dispersion, it can be useful in checking the homogeneity of the bulk distribution during curing. Moreover, it is important to verify the presence of aggregates as a consequence of the re-agglomeration tendency of CNFs during the gelation process. This characterization was carried out using a hot stage Mettler Toledo mod. FP82.

\section{Results and discussion}

Figure 1 shows the results of the morphological investigation for the $0.5 \%-\mathrm{CNF}$ nanocomposite. In particular, figures $1 \mathrm{a}$ and $1 \mathrm{~b}$ show the optical micrographs of the liquid mixture for the isothermal cure at $40^{\circ} \mathrm{C}$ at the beginning of the cure reaction and at the gel point, respectively. It is possible to observe that slight re-agglomeration is actually present during the gelation process. Nonetheless, this phenomenon is not strong enough to significantly compromise a fully cured nanocomposite with an even dispersion of CNFs. In fact, as a result of the TEM analysis (an example thereof is shown in figure 1c), the cured nanocomposites were characterized by a dispersion which is quite uniform. Similar micrographs were obtained for the $1 \%$-CNF nanocomposite and for the other temperatures and are not reported in this paper. 

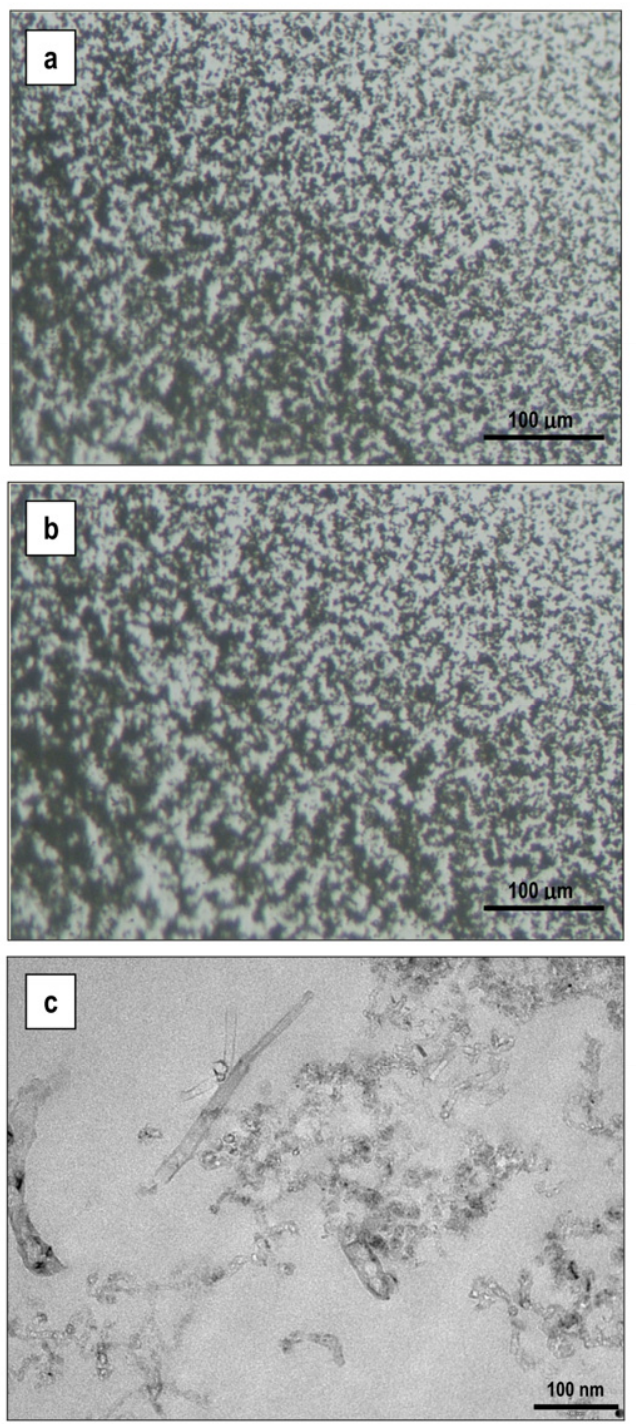

Figure 1

Table 1

\begin{tabular}{ccc}
\hline & \multicolumn{2}{c}{ Styrene content [\%] } \\
\hline Neat polyester & \multicolumn{2}{c}{$41.04 \pm 0.55$} \\
\hline & after mixing & after addition \\
\hline $\mathbf{0 . 5 \%}$ CNFs & $36.58 \pm 0.43$ & $40.73 \pm 0.36$ \\
$\mathbf{1} \%$ CNFs & $39.55 \pm 0.07$ & $40.68 \pm 0.43$ \\
\hline
\end{tabular}

The variation in the styrene content in the nanocomposites, due to styrene evaporation during the mixing process, was evaluated and the results are shown in table 1. It is possible to observe that only a little styrene evaporation occurs as a consequence of the mechanical stirring process. Moreover, this evaporation is more pronounced at $0.5 \mathrm{wt} \%$ 
because the lower viscosity of the mixture (due to a low content of CNFs) allows a greater amount of styrene to evaporate. In order to confirm this, we evaluated the styrene content in the neat polyester previously subjected to the same processing condition as the nanocomposites. After the mixing process, the neat polyester has a styrene content of $35.08 \%$ (not reported in table 1), which is lower than the values obtained for the nanocomposites, confirming that by increasing the CNF content, styrene evaporation is reduced.

This result concurs with those obtained in the TGA analyses performed at all the temperatures studied in this work. As an example, figure 2 shows the weight loss curves of the reacting systems during isothermal cure at $\mathrm{T}=25^{\circ} \mathrm{C}$. These plotted curves were normalized to the effective content of the styrene present in the mixture before curing. Analogous curves were obtained at the other temperatures and are not reported in this paper. Assuming that the styrene is the only diffusing material that causes mass loss in the UPs, the unfilled system shows the highest styrene loss rate before the gel point, while the CNFs filled system shows a decrease in the styrene consumption with respect to the neat system. This result, obtained during both the mixing phase and cure reaction can be explained by the fact that carbon nanofibers tend to increase the viscosity of the resin [20] and hamper styrene evaporation. The elbow transition observed in the curves from short time loss (linear slope) and long time loss can be associated to the vitrification of the systems so, after this point, any evaporation phenomenon is hindered. The second column of table 1 reports the styrene content after it was added to compensate the amount evaporated during the mixing process. It is possible to see that the systems in which the cure kinetics has been analyzed, have the same styrene content as the neat polyester. 


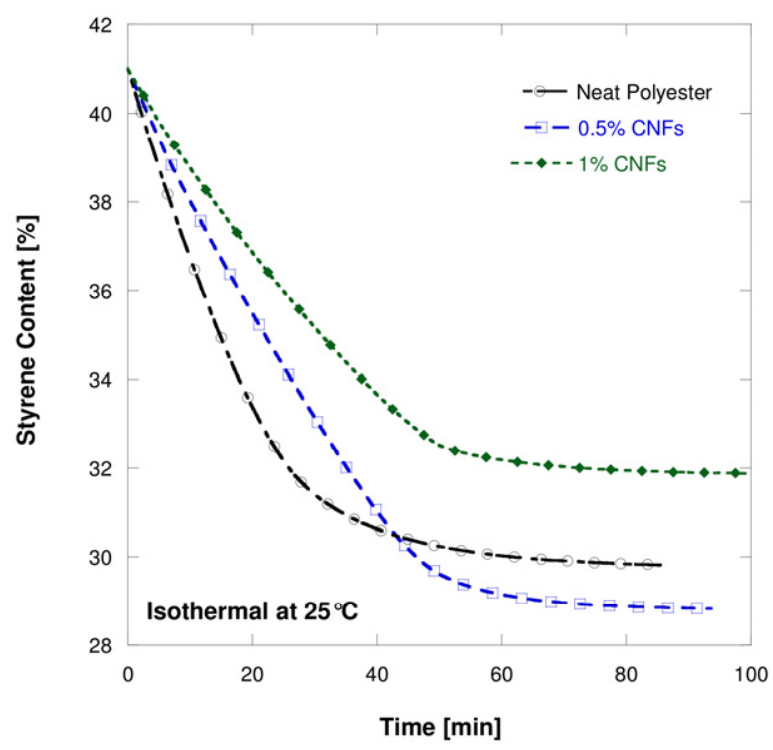

Figure 2

\subsection{Curing kinetics}

Once the correct styrene content was set in all the nanocomposite blends, an analysis of the cure kinetics was performed. Figure 3 reports the heat flow curves for the three selected systems at the same heating rate $\left(10^{\circ} \mathrm{C} / \mathrm{min}\right)$ and for the $0.5 \% \mathrm{CNFs}$ at different heating rates. It should be pointed out that in dynamic scans there is always a double reaction peak with a shoulder that is more visible as the scan rate increases. Double reaction peaks or peaks with shoulders are often detected in DSC traces during nonisothermal curing of UP resins [38]. Kubota [39] and Avella [40] confirmed that polyester homopolymerization was a cause of the highest temperature exothermic reaction in the DSC curves of the UP resin crosslinking. At higher temperatures, polyester coils possess enough energy to override steric hindrances and polyester homopolymerization becomes notable. Hence, as mentioned above, the first peak can be associated to the styrene polymerization coupled with the crosslinking reaction between styrene and polyester molecules, which, from activation energy measurements, is much easier than the homopolymerization of polyester itself. Lowering the heating rate of the test, the third exothermic reaction is less visible or disappears because at lower rates all the polyester chains are able to react with the styrene monomers. An increasing rate 
does not permit the styrene-polyester reaction to take place fully and so, at higher temperatures, the unreacted polyester chains can react with each other. Based on these considerations, we can assign the first double exothermic peak to the styrene-polyester copolymerization and styrene homopolymerization, while the single exothermic reaction at higher temperatures, referred above as the third peak, was due to polyester homopolymerization.

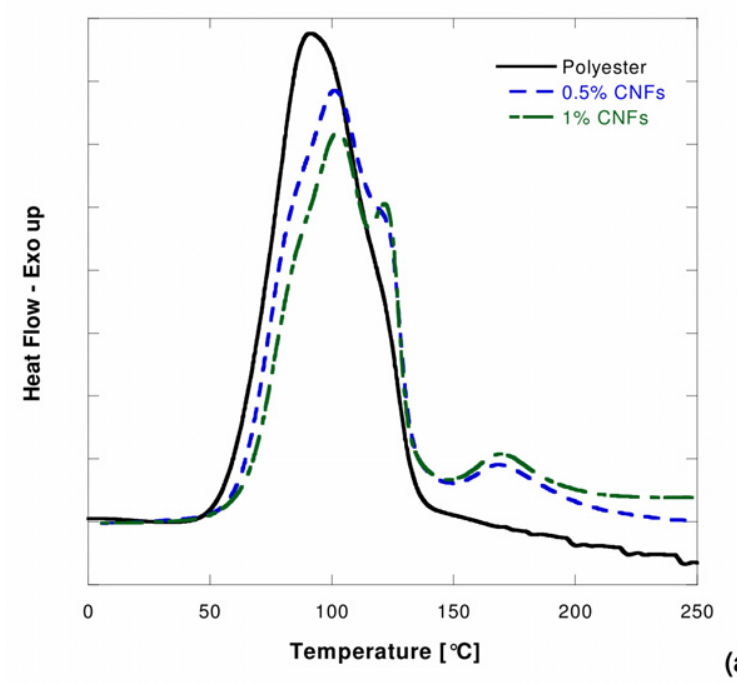

(a)

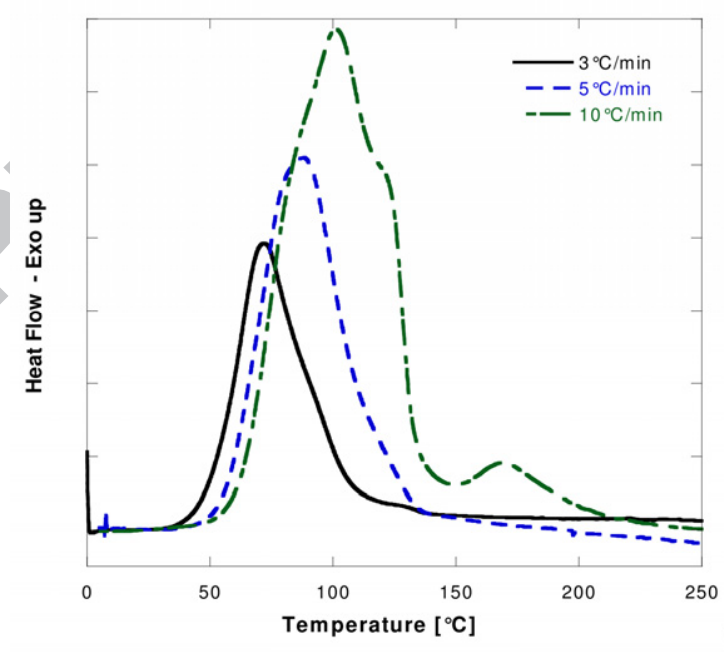

(b)

Figure 3

In figures $4 \mathrm{a}$ and $4 \mathrm{~b}$, DSC thermograms of isothermal tests are reported. Figure $4 \mathrm{a}$ shows the isothermal tests of the three systems at $\mathrm{T}=40^{\circ} \mathrm{C}$, whereas figure $4 \mathrm{~b}$ shows the isothermal thermograms of $0.5 \% \mathrm{CNF}$-loaded nanocomposites, performed at different temperatures. In tables 2 and 3, all the reaction characteristics of the calorimetric 
experiments have been summarized. In particular, the temperature at which there is a peak in the heat flow $\left(T_{\text {peak }}\right)$ and the total heat produced during dynamic cure $\left(\Delta H_{\text {dyn }}\right)$ have been reported for the dynamic scans (table 2) (all the values of the heat flow were normalized to the net amount of resin in the nanocomposite mixtures).
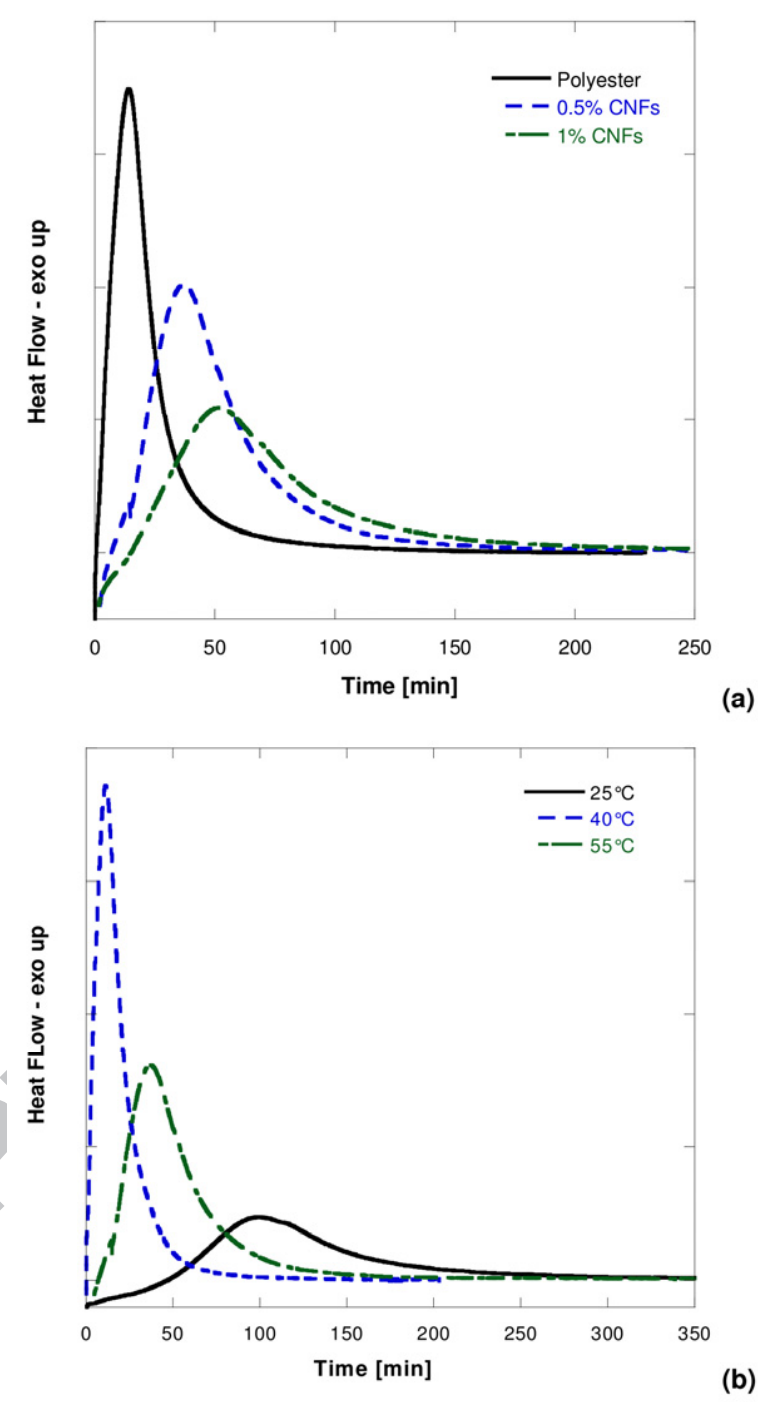

Figure 4

Table 2

\begin{tabular}{|c|c|c|c|c|c|c|}
\hline & \multicolumn{3}{|c|}{$\Delta \mathbf{H}_{\mathrm{dyn}}[\mathrm{J} / \mathrm{g}]$} & \multicolumn{3}{|c|}{$\mathbf{T}_{\text {peak }}\left[{ }^{\circ} \mathbf{C}\right]$} \\
\hline & $3^{\circ} \mathrm{C} / \mathrm{min}$ & $5^{\circ} \mathrm{C} / \mathrm{min}$ & $10^{\circ} \mathrm{C} / \mathrm{min}$ & $3^{\circ} \mathrm{C} / \mathrm{min}$ & $5^{\circ} \mathrm{C} / \mathrm{min}$ & $10^{\circ} \mathrm{C} / \mathrm{min}$ \\
\hline Neat Polyester & $287.4 \pm 8.4$ & $269.3 \pm 3.1$ & $239.9 \pm 1.6$ & $68.7 \pm 0.6$ & $77.5 \pm 1.0$ & $93.3 \pm 2.3$ \\
\hline $0.5 \%$ CNFs & $273.1 \pm 11.2$ & $265.1 \pm 15.4$ & $233.9 \pm 48.2$ & $70.6 \pm 4.8$ & $86.9 \pm 7.6$ & $94.6 \pm 6.9$ \\
\hline $1.0 \%$ CNFs & $239.6 \pm 4.4$ & $225.5 \pm 32.4$ & $187.5 \pm 14.5$ & $86.9 \pm 4.9$ & $94.5 \pm 2.6$ & $103.8 \pm 1.1$ \\
\hline
\end{tabular}


The parameters associated with isothermal tests (table 3 ) are the time at which the heat flow curve reaches a maximum $\left(t_{\text {peak }}\right)$, the induction time $\left(t_{\text {ind }}\right)$ calculated as the intersection between the horizontal right baseline and the heat flow curve, the heat related to isothermal curing $\left(\Delta H_{\text {iso }}\right)$ and the maximum degree of cure obtained in the final stage $\left(\alpha_{\max }\right)$. The degree of cure $\alpha$ is calculated as the ratio between the amount of heat generated, $H_{\mathrm{t}}$ at time $t$ and the total heat of reaction $H_{\mathrm{TOT}}$, which is calculated in dynamic scans:

$$
\alpha(t)=\frac{H_{t}}{H_{T}}=\frac{1}{H_{d y n}} \int_{0}^{t}\left(\frac{d H}{d t}\right) d t
$$

Table 3

\begin{tabular}{|c|c|c|c|c|c|c|}
\hline & \multicolumn{3}{|c|}{$\Delta \mathrm{H}_{\text {iso }}[\mathrm{J} / \mathbf{g}]$} & \multicolumn{3}{|c|}{$\alpha_{\max }[-]$} \\
\hline & $25^{\circ} \mathrm{C}$ & $40^{\circ} \mathrm{C}$ & $55^{\circ} \mathrm{C}$ & $25^{\circ} \mathrm{C}$ & $40^{\circ} \mathrm{C}$ & $55^{\circ} \mathrm{C}$ \\
\hline Neat Polyester & $185.2 \pm 18.5$ & $196.2 \pm 17.8$ & $213.9 \pm 4.7$ & $0.66 \pm 0.06$ & $0.74 \pm 0.06$ & $0.90 \pm 0.02$ \\
\hline $0.5 \%$ CNFs & $172.0 \pm 30.4$ & $192.9 \pm 11.0$ & $205.6 \pm 23.6$ & $0.63 \pm 0.10$ & $0.75 \pm 0.05$ & $0.83 \pm 0.13$ \\
\hline \multirow[t]{3}{*}{$1.0 \%$ CNFs } & $166.4 \pm 4.6$ & $179.0 \pm 7.8$ & $200.2 \pm 31.9$ & $0.69 \pm 0.02$ & $0.80 \pm 0.11$ & $0.92 \pm 0.07$ \\
\hline & \multicolumn{3}{|c|}{$t_{\text {peak }}[\mathrm{min}]$} & \multicolumn{3}{|c|}{$t_{\text {ind }}[\mathrm{min}]$} \\
\hline & $25^{\circ} \mathrm{C}$ & $40^{\circ} \mathrm{C}$ & $55^{\circ} \mathrm{C}$ & $25^{\circ} \mathrm{C}$ & $40^{\circ} \mathrm{C}$ & $55^{\circ} \mathrm{C}$ \\
\hline Neat Polyester & $72.2 \pm 10.5$ & $21.7 \pm 10.7$ & $9.9 \pm 2.3$ & $19.2 \pm 1.5$ & $8.3 \pm 3.6$ & $1.9 \pm 0.2$ \\
\hline $0.5 \%$ CNFs & $85.6 \pm 24.5$ & $28.4 \pm 0.5$ & $12.1 \pm 4.9$ & $46.7 \pm 7.4$ & $10.7 \pm 0.8$ & $2.5 \pm 0.5$ \\
\hline $1.0 \%$ CNFs & $112.9 \pm 24.3$ & $40.6 \pm 9.5$ & $16.4 \pm 2.1$ & $59.8 \pm 22.0$ & $14.7 \pm 0.5$ & $4.3 \pm 1.6$ \\
\hline
\end{tabular}

In figure 5, the trend of the degree of conversion was plotted as a function of temperature and time for dynamic (a) and isothermal (b) tests respectively, for the $0.5 \%$-loaded system. Similar plots were obtained for the other systems. As expected, the onset temperature of the cure reaction in dynamic tests increases with the heating rate while an incomplete resin cure is obtained in isothermal tests, with the maximum value of conversion increasing with the cure temperature. A linear dependence of the final degree of reaction on the isothermal curing temperature was found (figure 6), which is analogous to the trend found by Kenny and co-workers [3] for unsaturated polyester systems. No significant difference between the three systems was found with respect to 
the final degree of reaction and just one linear equation was sufficient for the interpolation of the data.

Based on an overall analysis of the DSC results, it is possible to make the following comments. The heat of reaction evolution in both dynamic and isothermal tests is delayed when CNFs are present in the blend and this delay depends on the nanofiber content. In fact, in both dynamic and isothermal tests, there is a shift in the exothermal peak toward higher temperatures and longer times, as shown in figures $3 \mathrm{a}$ and $4 \mathrm{a}$ respectively. Even $t_{\text {peak }}$ and $t_{\text {ind }}$ are shifted to higher values when increasing the CNF content. On the other hand, the maximum degree of reaction is not affected by the presence of the nanofibers.

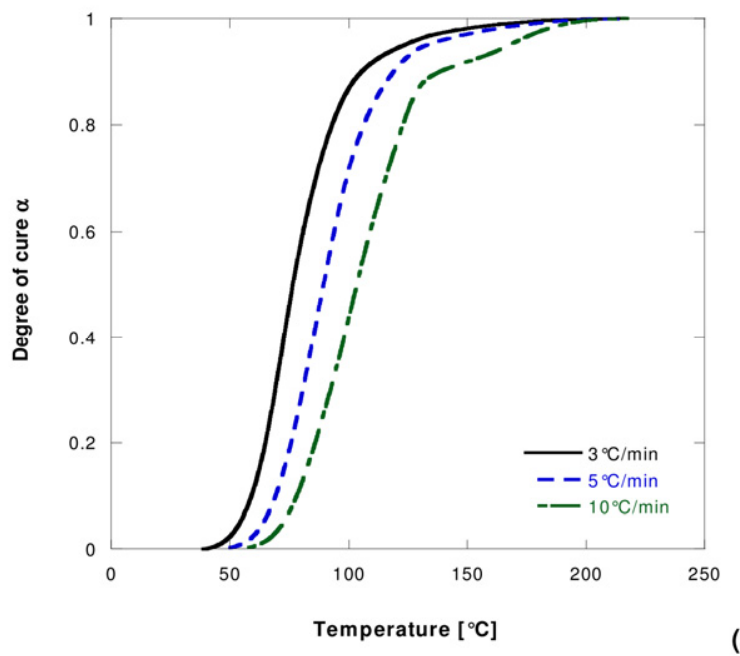

(a)

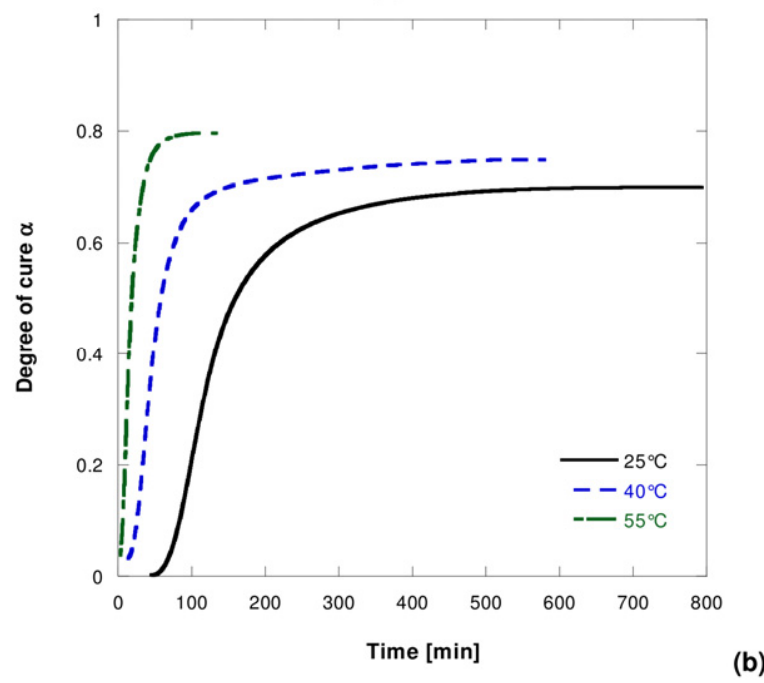

Figure 5 


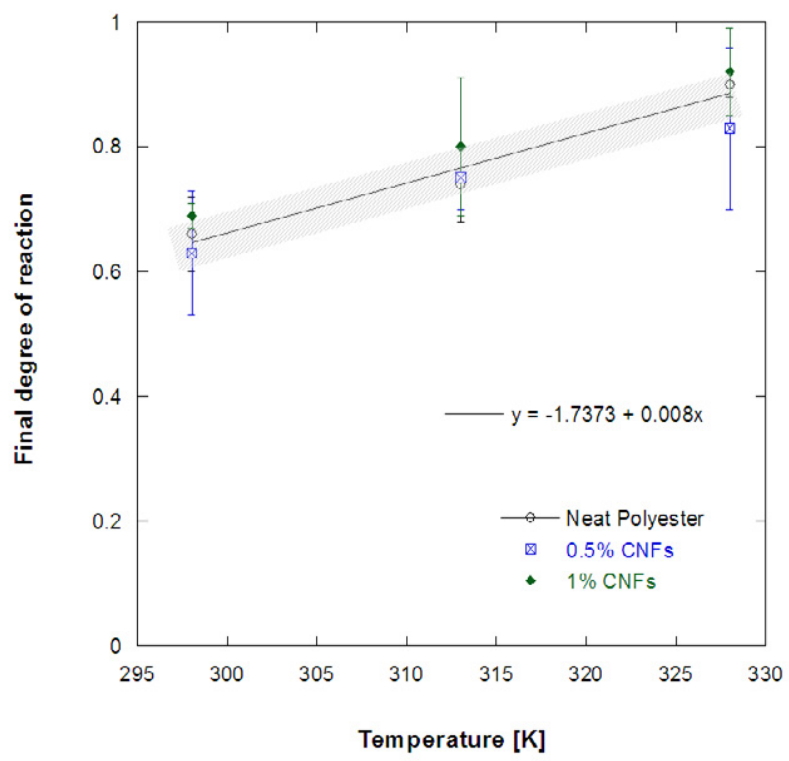

Figure 6

This delay, which does not produce a variation in the maximum extent of reaction, has been also observed in UP-carbon nanotube nanocomposites [41] while opposite results were reported on the curing of epoxy matrices, where an acceleration effect of the addition of carbon nanotubes has been reported [10]. It should be considered here the different nanofiber-matrix interactions expected in both cases. While for epoxy resins, the main interaction is represented by a strong non-covalent interaction of the amine hardener with the aromatic wall [10], in unsaturated polyesters, the free radicals scavenging activity of the carbon-based fillers can be considered as the main mechanism. As widely reported in the case of carbon nanotubes [42-45], untreated CNFs can be capable of entrapping the free-radicals generated by the initiator within their aromatic walls due to their huge surface area. As a result, the styrene can not react fully with the polyester molecules and is forced to self-polymerize. This consideration is also supported by our DSC results in figure 3a. In this figure, in fact, it is possible to see that the second and third peak, which are assigned to the self-polymerization of styrene and polyester respectively, are much more pronounced for the filled systems. 
As already mentioned, the model adopted for the cure kinetics was the one proposed by

Kenny et al. [3], where an incomplete cure reaction due to vitrification in the final conversion is considered:

$$
\frac{d \alpha}{d t}=K \alpha^{m}\left(\alpha_{\max }-\alpha\right)^{n}
$$

where $K$ is a kinetic rate constant and $m+n$ is the overall reaction order. The kinetic parameters for all the three systems at the different isothermal temperatures are reported in table 4 . This model successfully predicts the chemical progress of the cure reaction with time. As an example, model and experimental data for the isothermal tests of the UP+0.5\% CNF system are well compared in figure 7.

Table 4

\begin{tabular}{c|ccc|ccc|ccc}
\hline & \multicolumn{3}{|c|}{ Neat Polyester } & \multicolumn{3}{c|}{$\mathbf{0 . 5 \%} \mathbf{C N F s}$} & \multicolumn{3}{c}{$\mathbf{1 \%}_{\mathbf{~ C N F s}}$} \\
& $\mathbf{2 5 ^ { \circ } \mathbf { C }}$ & $\mathbf{4 0 ^ { \circ } \mathbf { C }}$ & $\mathbf{5 5}^{\circ} \mathbf{C}$ & $\mathbf{2 5}^{\circ} \mathbf{C}$ & $\mathbf{4 0} \mathbf{C}$ & $\mathbf{5 5 ^ { \circ } \mathbf { C }}$ & $\mathbf{2 5}^{\circ} \mathbf{C}$ & $\mathbf{4 0}^{\circ} \mathbf{C}$ & $\mathbf{5 5}^{\circ} \mathbf{C}$ \\
\hline $\mathbf{K}\left(^{*} \mathbf{1 0}^{-3} \mathbf{)}\right.$ & 1.47 & 3.14 & 3.72 & 0.94 & 2.13 & 3.67 & 0.53 & 1.18 & 2.10 \\
$\mathbf{m}$ & 0.50 & 0.51 & 0.53 & 0.60 & 0.62 & 0.67 & 0.66 & 0.52 & 0.57 \\
$\mathbf{n}$ & 1.31 & 1.55 & 1.55 & 1.60 & 1.47 & 1.53 & 1.26 & 1.28 & 1.42 \\
$\mathbf{m}+\mathbf{n}$ & 1.80 & 2.06 & 2.08 & 2.20 & 2.09 & 2.20 & 1.91 & 1.80 & 1.99 \\
\hline
\end{tabular}

The delaying effects of the CNFs are mainly reflected on the rate constant $K$ which decreases with the amount of carbon nanofibres. The overall order of reaction $m+n$, is close to 2 as typically reported for phenomenological models of thermosets curing [1, 3, 46] and remains practically constant with negligible changes with the CNFs content.

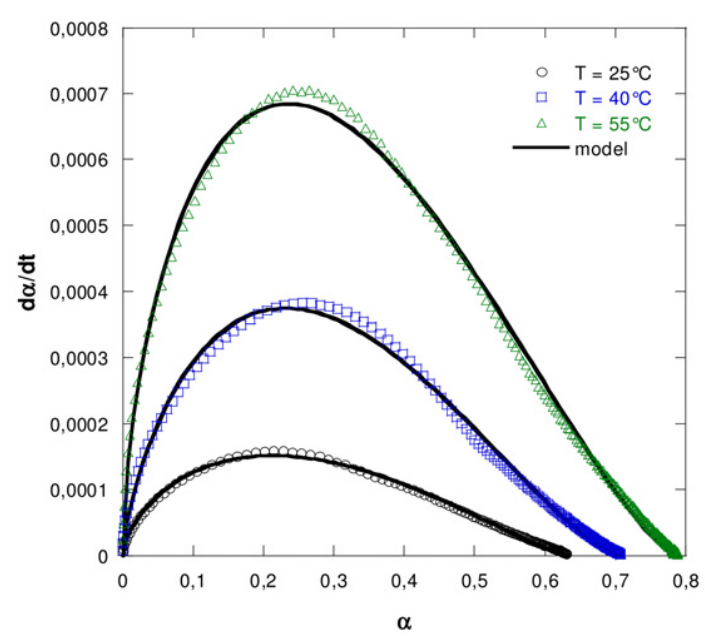

Figure 7 
The apparent activation energy and the pre-exponential factor can be obtained from the reaction constant $K$ at the different temperatures assuming an Arrhenius equation:

$$
\ln K=\ln K_{o}-E_{a} / R T
$$

The activation energies were then calculated from the plot of $\ln (K)$ vs $(1 / T)$ obtained in isothermal tests (figure 8). The obtained values are reported as an insert in figure 8 . The common trend is, as previously noted, that the cure reaction is delayed in temperature and time, upon increasing the CNF content (evidence of the delay is given by an increasing $E_{\mathrm{a}}$ value).

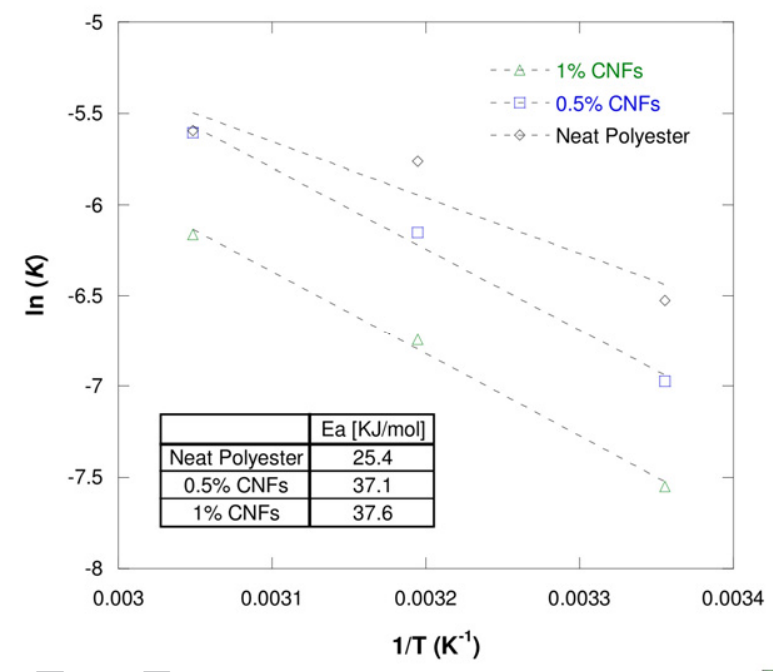

Figure 8

Whereas the isothermal traces are constituted by a single peak which can be correctly evaluated applying the kinetic model, dynamic cure is based on three different reaction peaks clearly visible in the heat flow curves (figure 3) and they need to be separated by a deconvolution process (in order to separate the three contributions to the total reaction pathway and to identify the individual kinetic steps). A model which properly fits the dynamic experimental was considered and the hypothesis was that each reaction obeys a rate law such as:

$$
\frac{d \alpha}{d t}=K \alpha^{m}(1-\alpha)^{n}
$$


supposing that every reaction was going to take place fully and the final conversion was

1. The overall expression for the reaction rate can be written as:

$$
\begin{aligned}
& \left(\frac{d \alpha}{d t}\right)_{\text {TOT }}=\left(\frac{d \alpha}{d t}\right)_{1}+\left(\frac{d \alpha}{d t}\right)_{2}+\left(\frac{d \alpha}{d t}\right)_{3}= \\
& =A K_{1} \alpha^{m_{1}}(1-\alpha)^{n_{1}}+B K_{2} \alpha^{m_{2}}(1-\alpha)^{n_{2}}+C K_{3} \alpha^{m_{3}}(1-\alpha)^{n_{3}}
\end{aligned}
$$

where $A, B$ and $C$ are the fractions of three different reactions.

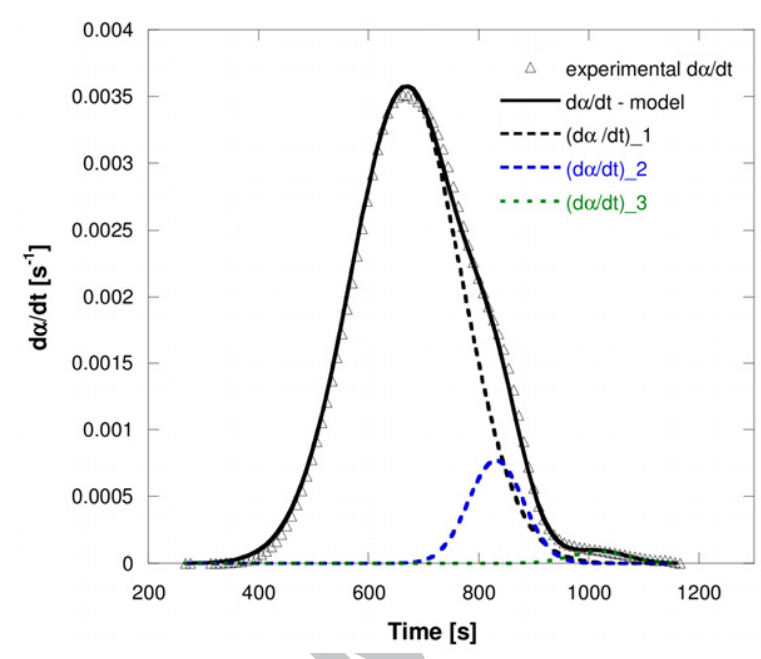

Figure 9

The calculations were performed as follows. First of all, the derivative of the overall extent of reaction curves $(d \alpha / d t)_{\text {тот }}$ were separated in three different sub-reactions. Each peak was integrated in time domain in order to obtain the extent of reaction of each single reaction and to evaluate the fraction coefficients $A, B$ and $C$. The maximum degree of reaction of each sub-reaction was then normalized to 1 and equation (5) was applied. As an example, figure 9 reports the overall reaction rate predicted by the model as a sum of the three reaction rates, for the $10^{\circ} \mathrm{C} / \mathrm{min}$-dynamic test of neat polyester. Table 5 reports all the calculated parameters. As it is possible to observe, the overall reaction rates $(m+n)$ for the three separated peaks in all the different systems do not significantly vary, confirming the effectiveness of the approach of a linear combination of the chosen kinetic equation. With respect to the $k$ values, we should analyze the three systems separately: it is clearly visible that the most important reaction, that is the first 
one in all the systems (fraction A is the highest), representing the copolymerization of the styrene with the polyester monomer, is also the reaction with the highest constant rate. This indicates that this reaction is the most thermally favoured. If we observe how the $k_{i}$ values vary from the neat system to the CNF charged systems, we note that the value for the second peak increases when increasing the CNF content in filled systems, indicating that the styrene homopolymerization reaction becomes more relevant. Regarding the third peak, assigned to the polyester homopolymerization, we can assert that no clear tendency for the importance of the reaction was detected from dynamic DSC tests.

It should be noticed that, since the curing process of a polyester resin is represented by several competing reactions with very different kinetics and activation energies, when the processing conditions change (as in the case of isothermal and dynamic processes) also the contribution of the individual reactions changes, leading to completely different reactions paths. For this reason it is highly difficult that the same kinetic equation and parameters can fit the experimental data collected. Then, the best possible approach is to have the same equation with different parameters that are able to describe the reaction in isothermal conditions (at different temperatures) and in dynamic conditions (at different heating rates).

\subsection{Chemorheology}

As already stated, the curing process was also investigated by monitoring the viscoelastic behaviour of the liquid reactive system during the chemical reaction, i.e. using rheological measurements. In fact, in this way it is possible to observe the temperature at which viscosity starts to grow, which means that the hardening stage has begun and to check how fast this stage takes place. In this case, both dynamic and isothermal tests were also performed under the same condition as the DSC tests. Basically, viscosity in temperature and time domains were plotted and analyzed. The 
plot of $\tan \delta$ as a function of time during isothermal tests was exploited to estimate the gel time, calculated as the minimum peak of the curve [3]. As an example, figure 10 reports a typical plot of the results for the isothermal test. Table 6 reports the gel times for all the studied materials and temperatures. It is possible to observe that these data can be correlated with heat flow peaks in isothermal DSC analysis.

Table 5

\begin{tabular}{|c|c|c|c|c|c|c|c|c|c|}
\hline \multirow[t]{2}{*}{$3^{\circ} \mathrm{C} / \mathrm{min}$} & \multicolumn{3}{|c|}{$\begin{array}{c}\text { Neat Polyester } \\
A=0.800 ; B=0.061 ; C=0.130\end{array}$} & \multicolumn{3}{|c|}{$\begin{array}{c}0.5 \% \text { CNFs } \\
A=0.756 ; B=0.112 ; C=0.117\end{array}$} & \multicolumn{3}{|c|}{$\begin{array}{c}1 \% \text { CNFs } \\
A=0.882 ; B=0.040 ; C=0.086\end{array}$} \\
\hline & $1^{\text {st }}$ Peak & $2^{\text {nd }}$ Peal & $3^{\text {rd }}$ Peak & $1^{\text {st }}$ Peak & $2^{\text {nd }}$ Pea & $3^{\text {rd }}$ Peak & $1^{\text {st }}$ Peak & $2^{\text {nd }}$ Peak & $3^{\text {rd }}$ Peak \\
\hline$k_{i}\left({ }^{*} 10^{-3}\right)$ & 5.16 & 0.62 & 0.33 & 4.12 & 0.96 & 0.34 & 3.39 & 0.18 & 0.45 \\
\hline $\mathrm{m}_{\mathrm{i}}$ & 0.77 & 0.74 & 0.79 & 0.77 & 0.74 & 0.79 & 0.77 & 0.78 & 0.72 \\
\hline $\mathbf{n}_{\mathbf{i}}$ & 0.86 & 0.89 & 0.82 & 0.86 & 0.89 & 0.84 & 0.85 & 0.81 & 0.92 \\
\hline \multirow[t]{2}{*}{$5^{\circ} \mathrm{C} / \mathrm{min}$} & \multicolumn{3}{|c|}{$\begin{array}{l}\text { Neat Polyester } \\
37 ; B=0.110 ; C=0.042\end{array}$} & \multicolumn{3}{|c|}{$\begin{array}{c}0.5 \% \text { CNFs } \\
A=0.858 B=0.078 ; C=0.069\end{array}$} & \multicolumn{3}{|c|}{$\begin{array}{c}1 \% \text { CNFs } \\
A=0.819 ; B=0.072 ; C=0.042\end{array}$} \\
\hline & $1^{\text {st }}$ Peak & $2^{\text {nd }}$ Peal & $3^{\text {rd }}$ Peak & $1^{\text {st }}$ Peak & $2^{\text {nd }}$ Pea & $3^{\text {rd }}$ Peak & $1^{\text {st }}$ Peak & $2^{\text {nd }}$ Peak & $3^{\text {rd }}$ Peak \\
\hline$k_{i}\left({ }^{*} 10^{-3}\right)$ & 7.15 & 1.11 & 0.28 & 6.07 & 0.82 & 0.22 & 5.81 & 1.24 & 0.18 \\
\hline $\mathbf{m}_{\mathbf{i}}$ & 0.78 & 0.77 & 0.78 & 0.78 & 0.76 & 0.77 & 0.79 & 0.75 & 0.76 \\
\hline $\mathbf{n}_{\mathbf{i}}$ & 0.85 & 0.86 & 0.83 & 0.85 & 0.87 & 0.77 & 0.84 & 0.88 & 0.73 \\
\hline \multirow[t]{2}{*}{$10^{\circ} \mathrm{C} / \mathrm{min}$} & \multicolumn{3}{|c|}{$\begin{array}{c}\text { Neat Polyester } \\
A=0.896 ; B=0.097 ; C=0.012\end{array}$} & \multicolumn{3}{|c|}{$\begin{array}{l}0.5 \% \text { CNFs } \\
; B=0.055 ; C=0.086\end{array}$} & \multicolumn{3}{|c|}{$\begin{array}{c}1 \% \text { CNFs } \\
A=0.841 ; B=0.069 ; C=0.092\end{array}$} \\
\hline & $1^{\text {st }}$ Peak & $2^{\text {nd }}$ Peal & $3^{\text {rd }}$ Peak & $1^{\text {st }}$ Peak & $2^{\text {nd }}$ Pea & $3^{\text {rd }}$ Peak & $1^{\text {st }}$ Peak & $2^{\text {nd }}$ Peak & $3^{\text {rd }}$ Peak \\
\hline$k_{i}\left({ }^{*} 10^{-3}\right)$ & 11.13 & 2.39 & 0.28 & 9.74 & 2.42 & 1.09 & 9.88 & 3.53 & 1.25 \\
\hline $\mathrm{m}_{\mathrm{i}}$ & 0.79 & 0.76 & 0.76 & 0.79 & 0.70 & 0.78 & 0.78 & 0.68 & 0.78 \\
\hline $\mathbf{n}_{\mathbf{i}}$ & 0.84 & 0.87 & 0.85 & 0.85 & 0.93 & 0.84 & 0.85 & 0.95 & 0.85 \\
\hline
\end{tabular}

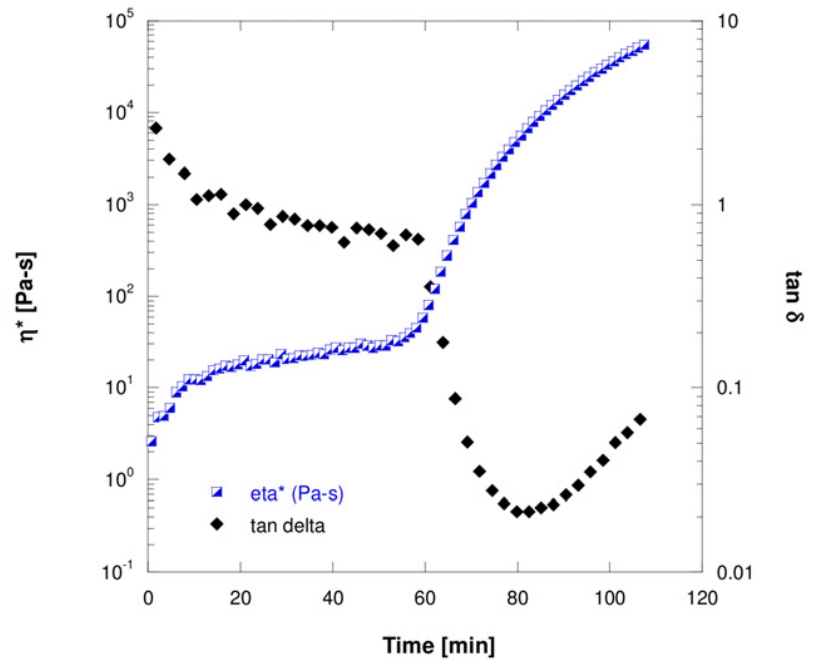

Figure 10 
Table 6

\begin{tabular}{|c|c|c|c|c|c|c|}
\hline & \multicolumn{3}{|c|}{ Gel Times [min] } & \multicolumn{3}{|c|}{$\alpha_{\text {gel }}[-]$} \\
\hline & $25^{\circ} \mathrm{C}$ & $40^{\circ} \mathrm{C}$ & $55^{\circ} \mathrm{C}$ & $25^{\circ} \mathrm{C}$ & $40^{\circ} \mathrm{C}$ & $55^{\circ} \mathrm{C}$ \\
\hline Neat Polyester & $79.5 \pm 4.0$ & $20.1 \pm 2.3$ & $8.7 \pm 0.7$ & $0.23 \pm 0.02$ & $0.24 \pm 0.03$ & $0.26 \pm 0.03$ \\
\hline $0.5 \%$ CNFs & $88.1 \pm 13.5$ & $26.7 \pm 4.8$ & $11.2 \pm 0.5$ & $0.23 \pm 0.03$ & $0.23 \pm 0.05$ & $0.30 \pm 0.07$ \\
\hline $1 \%$ CNFs & $118.5 \pm 12.5$ & $39.2 \pm 1.2$ & $16.0 \pm 3.9$ & $0.22 \pm 0.03$ & $0.23 \pm 0.04$ & $0.32 \pm 0.07$ \\
\hline
\end{tabular}

Figure 11 represents the trend of the viscosity in the temperature domain during the $5^{\circ} \mathrm{C} / \mathrm{min}$-dynamic scan for the three systems studied, whereas figure 12 shows the viscosity in the time domain during isothermal tests at $40^{\circ} \mathrm{C}$. As already encountered in the DSC tests, it is possible to observe the same general delay in the reaction rate in the nanocomposites in comparison to the neat matrix, and, in particular, the higher the nanofiber content, the more the delay effect is pronounced. It should be noted that the level of scatter in the viscosity profiles before gelation is due to the fact that the torque values produced by the resin flow are below the sensibility of the transducer.

Nonetheless, for the present study, the viscosity of the reactive system is relevant only close to the gel point.

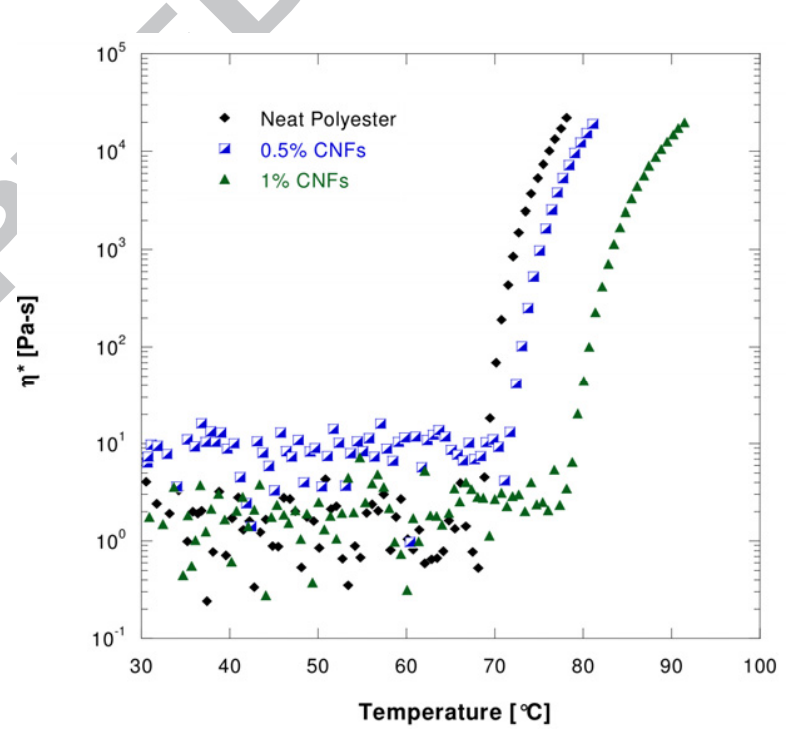

Figure 11 


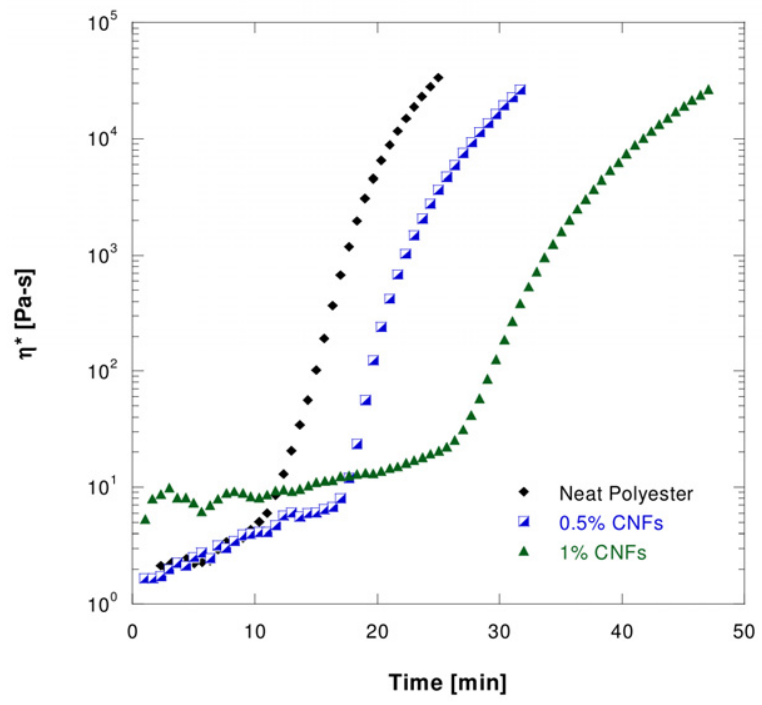

Figure 12

The relationship between viscosity and the degree of reaction in the interval before the gel point during isothermal cure, was described by using the empirical model developed by Castro and Makosco [36] and previously adopted for UP matrices for fiber reinforced composites [3]:

$$
\eta=K_{\eta} e^{\frac{E_{\eta}}{R T}}\left(\frac{\alpha_{g e l}}{\alpha_{g e l}-\alpha}\right)^{A+B \alpha}
$$

where $K_{\eta}$ is a pre-exponential factor, $E_{\eta}$ is the activation energy $A$ and $B$ are constants and $\alpha_{\text {gel }}$ represents the extent of reaction at the gel point. This equation was successfully applied to our experimental data. Table 7 reports all the parameters and in figure 13 experimental and modelling results are well compared for the three systems studied for the isothermal cure at $40^{\circ} \mathrm{C}$. Similarly, good results were obtained for all the temperatures analyzed. The A and B parameters are related to the rate of the variation of the viscosity as a consequence of the gelation. As a result of this modelling, it is possible to notice that they both decrease (B in modulus) when increasing the CNF content, giving further confirmation of the delay of the hardening process. 
Table 7

\begin{tabular}{|c|c|c|c|c|c|c|c|c|}
\hline & \multicolumn{6}{|c|}{ Cure Temperature } & \multirow[b]{3}{*}{$\mathrm{K}[\mathrm{Pa}-\mathrm{s}]$} & \multirow[b]{3}{*}{$E[\mathrm{KJ} / \mathrm{mol}]$} \\
\hline & \multicolumn{2}{|c|}{$25^{\circ} \mathrm{C}$} & \multicolumn{2}{|c|}{$40^{\circ} \mathrm{C}$} & \multicolumn{2}{|c|}{$55^{\circ} \mathrm{C}$} & & \\
\hline & $\mathbf{A}$ & B & A & B & $\mathbf{A}$ & B & & \\
\hline Neat Polyester & 7.0 & -22.2 & 13.2 & -44.0 & 10.6 & -24.0 & $3.4 \times 10^{-14}$ & 84.8 \\
\hline $0.5 \%$ CNFs & 4.8 & -10.9 & 10.4 & -35.8 & 9.3 & -19.8 & $5.0 \times 10^{-16}$ & 96.2 \\
\hline $1 \%$ CNFs & 3.9 & -9.5 & 9.7 & -33.8 & 8.2 & -12.6 & $4.0 \times 10^{-16}$ & 98.3 \\
\hline
\end{tabular}

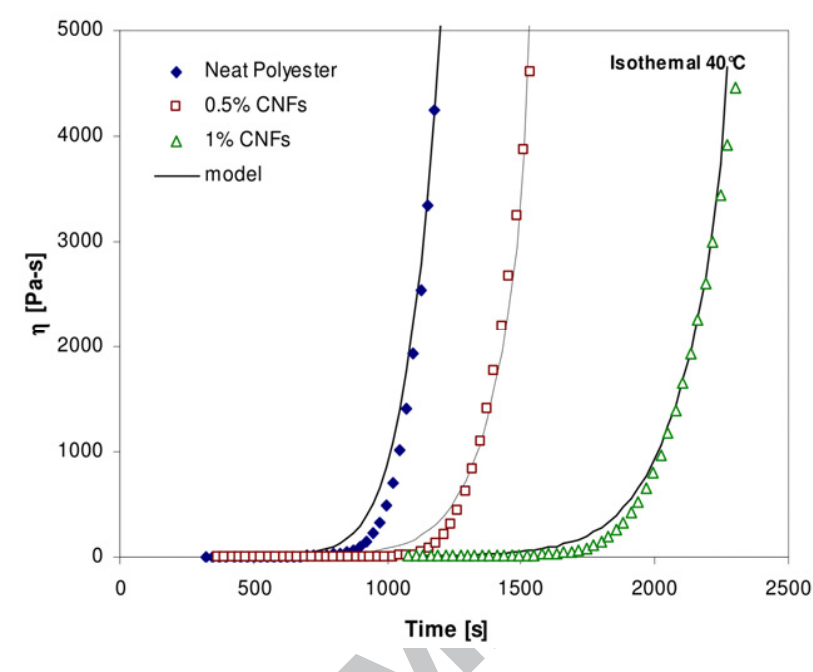

Figure 13

\section{Conclusions}

The cure kinetics of a CNF-filled UP resin was studied by means of thermal and chemorheological analyses. Both the DSC and rheology results have shown that the addition of carbon nanofibers to a UP resin produces a delay in the cure reaction, consisting of a shift in the exothermal reaction peak toward higher times and temperature in isothermal and dynamic tests, respectively. In rheological tests, the delay is clearly visible from the shift in the sharp increase in viscosity due to gelation.

However, the final degree of reaction of the UP resin is not affected by the presence of CNFs.

Phenomenological models that have already been effectively applied to UP resins for composite materials, were here utilized to successfully predict the thermal and rheological behaviour of the CNF-UP system. The kinetic parameters of the models 
adopted, which were calculated from experimental data, confirmed that the reaction rate is delayed when CNFs are added to the system. This conclusion is supported by considering that the main effect of CNFs on the unsaturated polyester resin during the curing process is represented by the free radicals scavenging activity of the carbonbased fillers. So, untreated CNFs are capable of entrapping the free-radicals generated by the initiator through an interaction with their aromatic walls and taking advantage of the huge surface area offered by this interaction.

\section{References}

[1] Lee DS, Han CD. A chemorheological model for the cure of unsaturated polyester resin. Polym Eng Sci (1987); 27: 955-963.

[2] Yang YS, James Lee L. Microstructure formation in the cure of unsaturated polyester resins. Polymer (1988); 29:1793-1800.

[3] Kenny JM, Maffezzoli A, Nicolais L. A model for the thermal and chemorheological behavior of thermoset processing: (II) Unsaturated polyester based composites. Compos Sci Technol (1990); 39:339-358.

[4] Chiu YY, Saito R, James Lee L. Modification of unsaturated polyester resins for viscosity control. Polymer (1996); 37: 2179-2190.

[5] Martín JL, Cadenato A, Salla JM. Comparative studies on the non-isothermal DSC curing kinetics of an unsaturated polyester resin using free radicals and empirical models. Thermochim Acta (1997); 306: 115-126.

[6] De la Caba K, Guerrero P, Mondragon I, Kenny JM. Comparative Study by and DSC FTIR - Techniques of an Unsaturated Polyester Resin Cured at Different Temperatures. Polym Int (1998); 45: 333-338.

[7] Kenny JM. Determination of autocatalytic kinetic model parameters describing thermoset cure. J Appl Polym Sci (1994); 51: 761-764. 
[8] Abdalla M, Dean D, Robinson P, Nyairo E. Cure behavior of epoxy/MWCNT nanocomposites: The effect of nanotube surface modification. Polymer (2008); 49: $3310-3317$.

[9] Xu WB, Zhou ZF, He PS, Pan WP. Cure behavior of epoxy resin-MMT-DETA nanocomposite. J Therm Anal Calorim (2004); 78: 113-124.

[10] Terenzi A, Vedova C, Lelli G, Mijovic J, Torre L, Valentini L, Kenny JM. Chemorheological behaviour of double-walled carbon nanotube-epoxy nanocomposites. Compos Sci Technol (2008); 68: 1862-1868.

[11] Xie H, Liu B, Yuan Z, Shen J, Cheng R. Cure Kinetics of Carbon Nanotube/Tetrafunctional Epoxy Nanocomposites by Isothermal Differential Scanning Calorimetry. J Polym Sci Pol Phys (2004); 42: 3701-3712.

[12] Hossain Beheshty M, Vafayan M, Poorabdollah M. Shrinkage Control and Kinetics Behaviour of Clay-Unsaturated Polyester Nanocomposites. Iranian Polym J (2006); 15: 841-849.

[13] Xu L, James Lee L. Kinetic analysis and mechanical properties of nanoclay reinforced unsaturated polyester (UP) resins cured at low temperatures. Polym Eng Sci (2005); 45: 496-509.

[14] Bashir MA. (2008) Effect of nanoclay dispersion on the processing of polyester nanocomposites McGill University - Master of Engineering Thesis.

[15] Cheng Y, Chen D, Wang C, He P. Cure Behavior of UP/OrgMMT/MEKP/Nanocomposites by the Dynamic Torsional Method. J Appl Polym Sci (2005); 97: 1-7.

[16] Rajabian M, Beheshty MH. Rheology and Flow Behavior of Suspensions of Nanosized Plate-Like Particles in Polyester Resins at the Startup of Shear Flows. Polym Composite (2009); 30: 399-407. 
[17] Zhou Y, Yang X, Jia D. Nonisothermal Curing Kinetics and Physical Properties of Unsaturated Polyester Modified with EA-POSS. Polym Int (2007); 56: 267-274.

[18] Gao J, Dong C, Du Y. Reaction kinetics and physical properties of unsaturated polyester modified with methylacyloxylpropyl-POSS. Int J Polym Mater (2010); 59: $1-14$.

[19] Gao J, Li S, Kong D. Cure behavior of unsaturated polyester/modified montmorillonite nanocomposites. Journal of Polymer Research DOI $10.1007 / \mathrm{s} 10965-010-9456-7$.

[20] Monti M, Terenzi A, Natali M, Gaztelumendi I, Markaide N, Kenny JM, Torre L. Development of unsaturated polyester matrix - carbon nanofibers nanocomposites with improved electrical properties. J Appl Polym Sci (2010); 117: 1658-1666.

[21] Battisti A, Skordos AA, Partridge IK. Percolation threshold of carbon nanotubes filled unsaturated polyesters. Compos Sci Technol (2010); 70: 633-637.

[22] Kayatin MJ, Davis VA. Viscoelasticity and Shear Stability of Single-Walled Carbon Nanotube/Unsaturated Polyester Resin Dispersions. Macromolecules (2009); 42: 6624-6632.

[23] Battisti A, Skordos AA, Partridge IK. Monitoring dispersion of carbon nanotubes in a thermosetting polyester resin. Compos Sci Technol (2009); 69: 1516-1520.

[24] Battisti A, Skordos AA, Partridge IK. Dielectric monitoring of carbon nanotube network formation in curing thermosetting nanocomposites. J Phys Appl Phys (2009); 42: 155402.

[25] Seyhan AT, Tanoglu M, Schulte K. Tensile mechanical behavior and fracture toughness of MWCNT and DWCNT modified vinyl-ester/polyester hybrid nanocomposites produced by 3-roll milling. Mat Sci Eng A- Struct (2009); 523: $85-92$. 
[26] Seyhan AT, De la Vega A, Tanoglu M, Schulte K. Thermal Curing Behavior of MWCNT Modified Vinyl Ester-Polyester Resin Suspensions Prepared with 3-Roll Milling Technique. J Polym Sci Pol Phys (2009); 47: 1511-1522.

[27] Simsek Y, Ozyuzer L, Seyhan A, Tanoglu M, Schulte K. Temperature dependence of electrical conductivity in double-wall and multi-wall carbon nanotube/polyester nanocomposites. J Mater Sci (2007); 42: 9689-9695.

[28] Wu S, Masaharu I, Natsuki T, Ni Q. Electrical Conduction and Percolation Behavior of Carbon Nanotubes/UPR Nanocomposites. J Reinf Plast Comp (2006); 25: 1957-1966.

[29] Natsuki T, Ni Q, Wu S. Temperature Dependence of Electrical Resistivity in Carbon Nanofiber/Unsaturated Polyester Nanocomposites. Polym Eng Sci (2008); 48: $1345-1350$.

[30] Wu S, Natsuki T, Kurashiki K, Ni Q, Masaharu I, Fujii Y. Conductivity stability of carbon nanofiber/unsaturated polyester nanocomposites. Adv Compos Mater (2007); 16: 195-206.

[31] Vera-Agullo J, Glória-Pereira A, Varela-Rizo H, Luis Gonzalez J, Martin-Gullon I. Comparative study of the dispersion and functional properties of multiwall carbon nanotubes and helical-ribbon carbon nanofibers in polyester nanocomposites. Compos Sci Technol (2009); 69: 1521-1532.

[32] Ton-That MT, Cole KC, Jen CK, Franca DR. Polyester cure monitoring by means of different techniques. Polym Composite (2000); 21: 605-618.

[33] Cadenato A, Salla JM, Ramis X, Morancho JM, Marroyo LM, Martin JL. Determination of gel and vitrification times of thermoset curing process by means of TMA, DMTA and DSC techniques. J Therm Anal (1997); 49: 269-279.

[34] Legros N, Jen CK, Ihara I. Ultrasonic evaluation and application of oriented polymer rods. Ultrasonics (1999); 37: 291-297. 
[35] Lionetto F, Rizzo R, Luprano VAM, Maffezzoli A. Phase transformations during the cure of unsaturated polyester resins. Mat Sci Eng A - Struct (2004); 370: 284287.

[36] Castro JM, Macosko C. Studies of mold filling and curing in the reaction injection molding process. AICHE Journal (1982); 28: 251-260.

[37] Vera-Agullo J, Varela-Rizo H, Conesa JA, Almansa C, Merino C, Martin-Gullon I. Evidence for growth mechanism and helix-spiral cone structure of stacked-cup carbon nanofibers. Carbon (2007); 45: 2751-2758.

[38] Martin JL. Kinetic analysis of two peaks in the curing of an unsaturated polyester resin catalyzed with MEKP and Cobalt octoate. Polym Eng. Sci. (2007); 47 (1): $62-70$.

[39] Kubota H. Curing of highly reactive polyester resin under pressure: kinetic studies by differential scanning calorimetry. J. Appl. Polym. Sci. (1975); 19: 2279-2297.

[40] Avella M, Martuscelli E, Mazzola M. Kinetic study of the cure reaction of unsaturated polyester resins. J. Therm. Anal. (1985); 30: 1359-1366.

[41] Monti M. (2009). Advances in polymer nanocomposites with high aspect ratio carbon nanoparticles for damage tolerance sensing in fiber reinforced composites. University of Perugia - PhD Thesis.

[42] Martınez A, Galano A. Free Radical Scavenging Activity of Ultrashort SingleWalled Carbon Nanotubes with Different Structures through Electron Transfer Reactions. J. Phys. Chem. C (2010); 114: 8184-8191.

[43] Zeynalov EB, Friedrich JF. Antioxidative Activity of Carbon Nanotube and Nanofiber. The Open Materials Science Journal (2008); 2: 28-34.

[44] Munirasu S, Albuerne J, Boschetti-de-Fierro A, Abetz V. Functionalization of Carbon Materials using the Diels-Alder Reaction. Macromol. Rapid Commun. (2010); 31: 574-579. 
[45] Fenoglio I, Tomatis M, Lison D, Muller J, Fonseca A, Nagy JB, Fubini B.

Reactivity of carbon nanotubes: Free radical generation or scavenging activity?

Free Radical Biology \& Medicine (2006); 40: 1227-1233.

[46] Kamal MR, Sourour S. Kinetics and thermal characterization of thermoset cure.

Polym Eng. Sci. (1973); 13 (1): 59-64 


\section{Figure captions}

Figure 1: Optical micrographs before curing (a) and after the gel point (b), TEM image (c) of $0.5 \%$-CNF fully cured nanocomposite.

Figure 2 : Weight loss curves for isothermal curing at $25^{\circ} \mathrm{C}$ for the three systems. Figure 3 : DSC thermogram of $10^{\circ} \mathrm{C} / \mathrm{min}$ dynamic scans for the studied systems (a) and $0.5 \%$ CNFs system ad different heating rates $(b)$.

Figure 4 : Isothermal DSC thermograms of different systems at $\mathrm{T}=40^{\circ} \mathrm{C}$ (a) and of $0.5 \%$-CNFs at different temperatures (b) .

Figure 5: Degree of cure of the $0.5 \%$-CNFs during dynamic scans at different scan rates (a) and mean values obtained for isothermal tests at different cure temperatures (b).

Figure 6: Fitting of the experimental final degree of reaction vs isothermal temperature Figure 7: Comparison of experimental data and model for isothermal tests for the UP + $0.5 \%$ CNFs system.

Figure 8: Calculation of the apparent activation energies.

Figure 9: The calculated do/dt versus time curve $(-)$, and the experimental data $(\Delta)$. The three simulated peaks are drawn too.

Figure 10: Typical rheological outcome, for a isothermal test at $25^{\circ} \mathrm{C}$, of the neat resin. Figure 11: Evolution of the viscosity during dynamic tests at $5^{\circ} \mathrm{C} / \mathrm{min}$ for the neat polyester, the $0.5 \%$ and the $1 \%$ CNF nanocomposites.

Figure 12: Evolution of the viscosity during isothermal tests at $40^{\circ} \mathrm{C}$ for the neat polyester, $0.5 \%$ and $1 \% \mathrm{CNF}$ nanocomposites.

Figure 13: Curves of relative viscosity versus time for the three studied systems: experimental data and model prediction. 


\section{Table captions}

Table 1: Styrene content in all the systems analyzed, before and after the addition.

Table 2: DSC results for dynamic tests.

Table 3: DSC results for isothermal tests

Table 4: Kinetic parameter of isothermal cure.

Table 5: Kinetic parameters of dynamic tests.

Table 6: Gel times and degree of reaction at the gel point as calculated by rheological tests.

Table 7: Kinetic parameters of the rheological model. 


\section{Highlights}

We study the effect of CNFs on the cure kinetics of unsaturated polyester resin.

A kinetic model was applied to DSC and rheological results.

A delaying effect on the cure was observed when CNFs are added to the matrix.

Scavenging activity of CNFs on the free radicals causes the delaying effect. 
Table 1: Styrene content in all the systems analyzed, before and after the addition.

Styrene content [\%]

\begin{tabular}{ccc}
\hline Neat polyester & \multicolumn{2}{c}{$41.04 \pm 0.55$} \\
\hline & after mixing & after adding \\
\hline $\mathbf{0 . 5} \%$ CNFs & $36.58 \pm 0.43$ & $40.73 \pm 0.36$ \\
$\mathbf{1} \%$ CNFs & $39.55 \pm 0.07$ & $40.68 \pm 0.43$ \\
\hline
\end{tabular}


Table 2: DSC results for dynamic tests.

\begin{tabular}{|c|c|c|c|c|c|c|}
\hline & \multicolumn{3}{|c|}{$\Delta \mathbf{H}_{\mathrm{dyn}}[\mathrm{J} / \mathrm{g}]$} & \multicolumn{3}{|c|}{$\mathbf{T}_{\text {peak }}\left[{ }^{\circ} \mathbf{C}\right]$} \\
\hline & $3^{\circ} \mathrm{C} / \mathrm{min}$ & $5^{\circ} \mathrm{C} / \mathrm{min}$ & $10^{\circ} \mathrm{C} / \mathrm{min}$ & $3^{\circ} \mathrm{C} / \mathrm{min}$ & $5^{\circ} \mathrm{C} / \mathrm{min}$ & $10^{\circ} \mathrm{C} / \mathrm{min}$ \\
\hline Neat Polyester & $287.4 \pm 8.4$ & $269.3 \pm 3.1$ & $239.9 \pm 1.6$ & $68.7 \pm 0.6$ & $77.5 \pm 1.0$ & $93.3 \pm 2.3$ \\
\hline $0.5 \%$ CNFs & $273.1 \pm 11.2$ & $265.1 \pm 15.4$ & $233.9 \pm 48.2$ & $70.6 \pm 4.8$ & $86.9 \pm 7.6$ & $94.6 \pm 6.9$ \\
\hline $1.0 \%$ CNFs & $239.6 \pm 4.4$ & $225.5 \pm 32.4$ & $187.5 \pm 14.5$ & $86.9 \pm 4.9$ & $94.5 \pm 2.6$ & $103.8 \pm 1.1$ \\
\hline
\end{tabular}


Table 3: DSC results for isothermal tests

\begin{tabular}{|c|c|c|c|c|c|c|}
\hline & \multicolumn{3}{|c|}{$\Delta H_{\text {iso }}[J / g]$} & \multicolumn{3}{|c|}{$\alpha_{\max }[-]$} \\
\hline & $25^{\circ} \mathrm{C}$ & $40^{\circ} \mathrm{C}$ & $55^{\circ} \mathrm{C}$ & $25^{\circ} \mathrm{C}$ & $40^{\circ} \mathrm{C}$ & $55^{\circ} \mathrm{C}$ \\
\hline Neat Polyester & $185.2 \pm 18.5$ & $196.2 \pm 17.8$ & $213.9 \pm 4.7$ & $0.66 \pm 0.06$ & $0.74 \pm 0.06$ & $0.90 \pm 0.02$ \\
\hline $0.5 \%$ CNFs & $172.0 \pm 30.4$ & $192.9 \pm 11.0$ & $205.6 \pm 23.6$ & $0.63 \pm 0.10$ & $0.75 \pm 0.05$ & $0.83 \pm 0.13$ \\
\hline \multirow[t]{3}{*}{$1.0 \%$ CNFs } & $166.4 \pm 4.6$ & $179.0 \pm 7.8$ & $200.2 \pm 31.9$ & $0.69 \pm 0.02$ & $0.80 \pm 0.11$ & $0.92 \pm 0.07$ \\
\hline & \multicolumn{3}{|c|}{$t_{\text {peak }}[\mathrm{min}]$} & \multicolumn{3}{|c|}{$t_{\text {ind }}[\min ]$} \\
\hline & $25^{\circ} \mathrm{C}$ & $40^{\circ} \mathrm{C}$ & $55^{\circ} \mathrm{C}$ & $25^{\circ} \mathrm{C}$ & $40^{\circ} \mathrm{C}$ & $55^{\circ} \mathrm{C}$ \\
\hline Neat Polyester & $72.2 \pm 10.5$ & $21.7 \pm 10.7$ & $9.9 \pm 2.3$ & $19.2 \pm 1.5$ & $8.3 \pm 3.6$ & $1.9 \pm 0.2$ \\
\hline $0.5 \%$ CNFs & $85.6 \pm 24.5$ & $28.4 \pm 0.5$ & $12.1 \pm 4.9$ & $46.7 \pm 7.4$ & $10.7 \pm 0.8$ & $2.5 \pm 0.5$ \\
\hline $1.0 \%$ CNFs & $112.9 \pm 24.3$ & $40.6 \pm 9.5$ & $16.4 \pm 2.1$ & $59.8 \pm 22.0$ & $14.7 \pm 0.5$ & $4.3 \pm 1.6$ \\
\hline
\end{tabular}


Table 4: Kinetic parameter of isothermal cure.

\begin{tabular}{c|ccc|ccc|ccc}
\hline & \multicolumn{3}{|c|}{ Neat Polyester } & \multicolumn{3}{c|}{$\mathbf{0 . 5 \%} \mathbf{C N F s}$} & \multicolumn{3}{c}{$\mathbf{1 \%} \mathbf{~ C N F s}$} \\
& $\mathbf{2 5}^{\circ} \mathbf{C}$ & $\mathbf{4 0}^{\circ} \mathbf{C}$ & $\mathbf{5 5}^{\circ} \mathbf{C}$ & $\mathbf{2 5}^{\circ} \mathbf{C}$ & $\mathbf{4 0}^{\circ} \mathbf{C}$ & $\mathbf{5 5}^{\circ} \mathbf{C}$ & $\mathbf{2 5}^{\circ} \mathbf{C}$ & $\mathbf{4 0}^{\circ} \mathbf{C}$ & $\mathbf{5 5}^{\circ} \mathbf{C}$ \\
\hline $\mathbf{K}\left({ }^{*} \mathbf{1} \mathbf{0}^{-3}\right)$ & 1.47 & 3.14 & 3.72 & 0.94 & 2.13 & 3.67 & 0.53 & 1.18 & 2.10 \\
$\mathbf{m}$ & 0.50 & 0.51 & 0.53 & 0.60 & 0.62 & 0.67 & 0.66 & 0.52 & 0.57 \\
$\mathbf{n}$ & 1.31 & 1.55 & 1.55 & 1.60 & 1.47 & 1.53 & 1.26 & 1.28 & 1.42 \\
$\mathbf{m}+\mathbf{n}$ & 1.80 & 2.06 & 2.08 & 2.20 & 2.09 & 2.20 & 1.91 & 1.80 & 1.99 \\
\hline
\end{tabular}


Table 5: Kinetic parameters of dynamic tests.

\begin{tabular}{|c|c|c|c|c|c|c|c|c|c|}
\hline \multirow[t]{2}{*}{$3^{\circ} \mathrm{C} / \mathrm{min}$} & \multicolumn{3}{|c|}{$\begin{array}{l}\text { Neat Polyester } \\
800 ; B=0.061 ; C=0.130\end{array}$} & \multicolumn{3}{|c|}{$\begin{array}{c}0.5 \% \text { CNFs } \\
A=0.756 ; B=0.112 ; C=0.117\end{array}$} & \multicolumn{3}{|c|}{$\begin{array}{c}1 \% \text { CNFs } \\
A=0.882 ; B=0.040 ; C=0.086\end{array}$} \\
\hline & $1^{\text {st }}$ Peak & $2^{\text {nd }}$ Peak & $3^{\text {rd }}$ Peak & $1^{\text {st }}$ Peak & $2^{\text {nd }}$ Peak & $3^{\text {rd }}$ Peak & $1^{\text {st }}$ Peak & $2^{\text {nd }}$ Peak & $3^{\text {rd }}$ Peak \\
\hline$k_{i}\left({ }^{\star} 10^{-3}\right)$ & 5.16 & 0.62 & 0.33 & 4.12 & 0.96 & 0.34 & 3.39 & 0.18 & 0.4 \\
\hline $\mathrm{m}_{\mathrm{i}}$ & 0.77 & 0.74 & 0.79 & 0.77 & 0.74 & 0.79 & 0.77 & 0.78 & 0.72 \\
\hline $\mathrm{n}_{\mathrm{i}}$ & 0.86 & 0.89 & 0.82 & 0.86 & 0.89 & 0.84 & 0.85 & 0.81 & .92 \\
\hline \multirow[t]{2}{*}{$5^{\circ} \mathrm{C} / \mathrm{min}$} & \multicolumn{3}{|c|}{$\begin{array}{l}\text { Neat Polyester } \\
37 ; B=0.110 ; C=0.042\end{array}$} & \multicolumn{3}{|c|}{$\begin{array}{c}\text { 0.5\%CNFs } \\
A=0.858 B=0.078 ; C=0.069\end{array}$} & \multicolumn{3}{|c|}{$\begin{array}{c}1 \% \text { CNFs } \\
A=0.819 ; B=0.072 ; C=0.042\end{array}$} \\
\hline & $1^{\text {st }}$ Peak & $2^{\text {nd }}$ Peak & $3^{\text {rd }}$ Peak & $1^{\text {st }}$ Peak & $2^{\text {nd }}$ Peak & $3^{\text {rd }}$ Peak & $1^{\text {st }}$ Peak & $2^{\text {nd }}$ Peak & $3^{\text {rd }}$ Peak \\
\hline$k_{i}\left({ }^{*} 10^{-3}\right)$ & 7.15 & 1.11 & 0.28 & 6.07 & 0.82 & 0.22 & 5.81 & 1.24 & 0.18 \\
\hline $\mathbf{m}_{\mathbf{i}}$ & 0.78 & 0.77 & 0.78 & 0.78 & 0.76 & 0.77 & 0.79 & 0.75 & 0.76 \\
\hline $\mathbf{n}_{\mathbf{i}}$ & 0.85 & 0.86 & 0.83 & 0.85 & 0.87 & 0.77 & 0.84 & 0.88 & 0.73 \\
\hline \multirow[t]{2}{*}{$10^{\circ} \mathrm{C} / \mathrm{min}$} & \multicolumn{3}{|c|}{ Neat Polyester } & \multicolumn{3}{|c|}{$\begin{array}{c}0.5 \% \text { CNFs } \\
A=0.868 ; B=0.055 ; C=0.086\end{array}$} & \multicolumn{3}{|c|}{$\begin{array}{c}1 \% \text { CNFs } \\
A=0.841 ; B=0.069 ; C=0.092\end{array}$} \\
\hline & $1^{\text {st }}$ Peak & $2^{\text {nd }}$ Peak & $3^{\text {rd }}$ Peak & $1^{\text {st }}$ Peak & $2^{\text {nd }}$ Peak & $3^{\text {rd }}$ Peak & $1^{\text {st }}$ Peak & $2^{\text {nd }}$ Peak & $3^{\text {rd }}$ Peak \\
\hline$k_{i}\left({ }^{*} 10^{-3}\right)$ & 11.13 & 2.39 & 0.28 & 9.74 & 2.42 & 1.09 & 9.88 & 3.53 & 1.25 \\
\hline $\mathbf{m}_{\mathbf{i}}$ & 0.79 & 0.76 & 0.76 & 0.79 & 0.70 & 0.78 & 0.78 & 0.68 & 0.78 \\
\hline $\mathbf{n}_{\mathbf{i}}$ & 0.84 & 0.87 & 0.85 & 0.85 & 0.93 & 0.84 & 0.85 & 0.95 & 0.85 \\
\hline
\end{tabular}


Table 6: Gel times as calculated by rheological tests.

\begin{tabular}{|c|c|c|c|c|c|c|}
\hline & \multicolumn{3}{|c|}{ Gel Times [min] } & \multicolumn{3}{|c|}{$\alpha_{\text {gel }}[-]$} \\
\hline & $25^{\circ} \mathrm{C}$ & $40^{\circ} \mathrm{C}$ & $55^{\circ} \mathrm{C}$ & $25^{\circ} \mathrm{C}$ & $40^{\circ} \mathrm{C}$ & $55^{\circ} \mathrm{C}$ \\
\hline Neat Polyester & $79.5 \pm 4.0$ & $20.1 \pm 2.3$ & $8.7 \pm 0.7$ & $0.23 \pm 0.02$ & $0.24 \pm 0.03$ & $0.26 \pm 0.03$ \\
\hline $0.5 \%$ CNFs & $88.1 \pm 13.5$ & $26.7 \pm 4.8$ & $11.2 \pm 0.5$ & $0.23 \pm 0.03$ & $0.23 \pm 0.05$ & $0.30 \pm 0.07$ \\
\hline $1 \%$ CNFs & $118.5 \pm 12.5$ & $39.2 \pm 1.2$ & $16.0 \pm 3.9$ & $0.22 \pm 0.03$ & $0.23 \pm 0.04$ & $0.32 \pm 0.07$ \\
\hline
\end{tabular}


Tab. 7: Kinetic parameters of the rheological model.

\begin{tabular}{|c|c|c|c|c|c|c|c|c|}
\hline & \multicolumn{6}{|c|}{ Cure Temperature } & & \\
\hline & \multicolumn{2}{|c|}{$25^{\circ} \mathrm{C}$} & \multicolumn{2}{|c|}{$40^{\circ} \mathrm{C}$} & \multicolumn{2}{|c|}{$55^{\circ} \mathrm{C}$} & & \\
\hline & A & B & A & B & A & B & $\mathrm{K}[\mathrm{Pa}-\mathrm{s}]$ & $\mathrm{E}[\mathrm{KJ} / \mathrm{mol}]$ \\
\hline Neat Polyester & 7.0 & -22.2 & 13.2 & -44.0 & 10.6 & -24.0 & $3.4 \times 10^{-14}$ & 84.8 \\
\hline $0.5 \%$ CNFs & 4.8 & -10.9 & 10.4 & -35.8 & 9.3 & -19.8 & $5.0 \times 10^{-16}$ & 96.2 \\
\hline $1 \%$ CNFs & 3.9 & -9.5 & 9.7 & -33.8 & 8.2 & -12.6 & $4.0 \times 10^{-16}$ & 98.3 \\
\hline
\end{tabular}



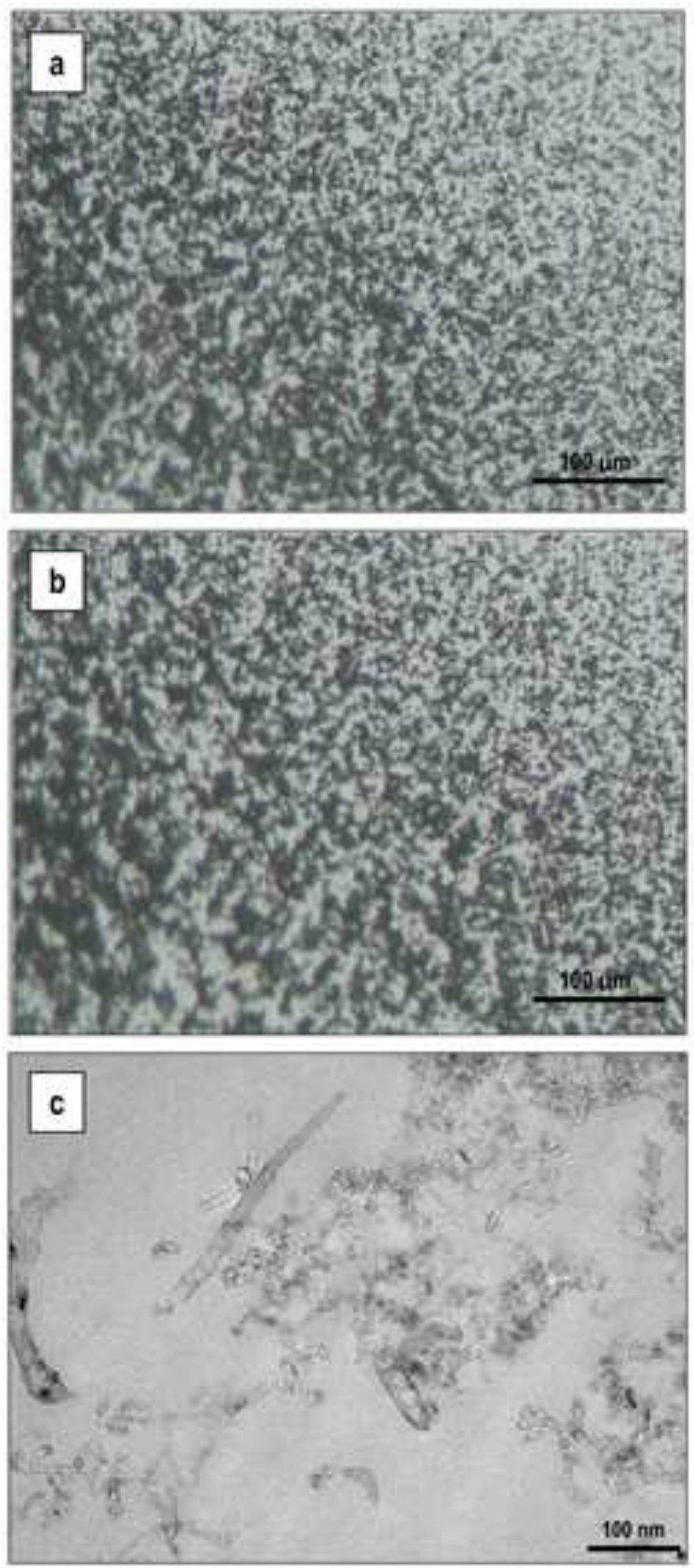


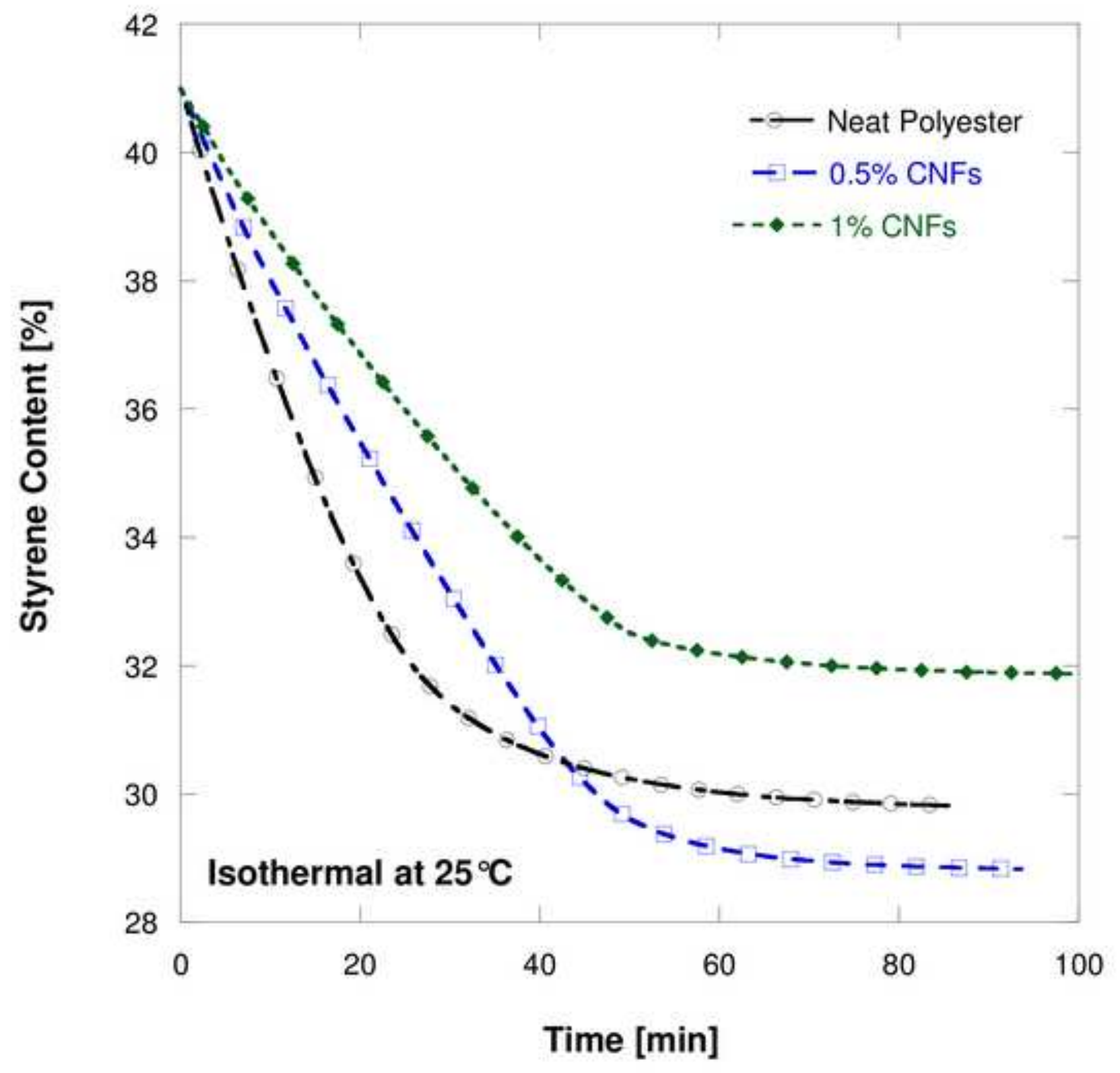




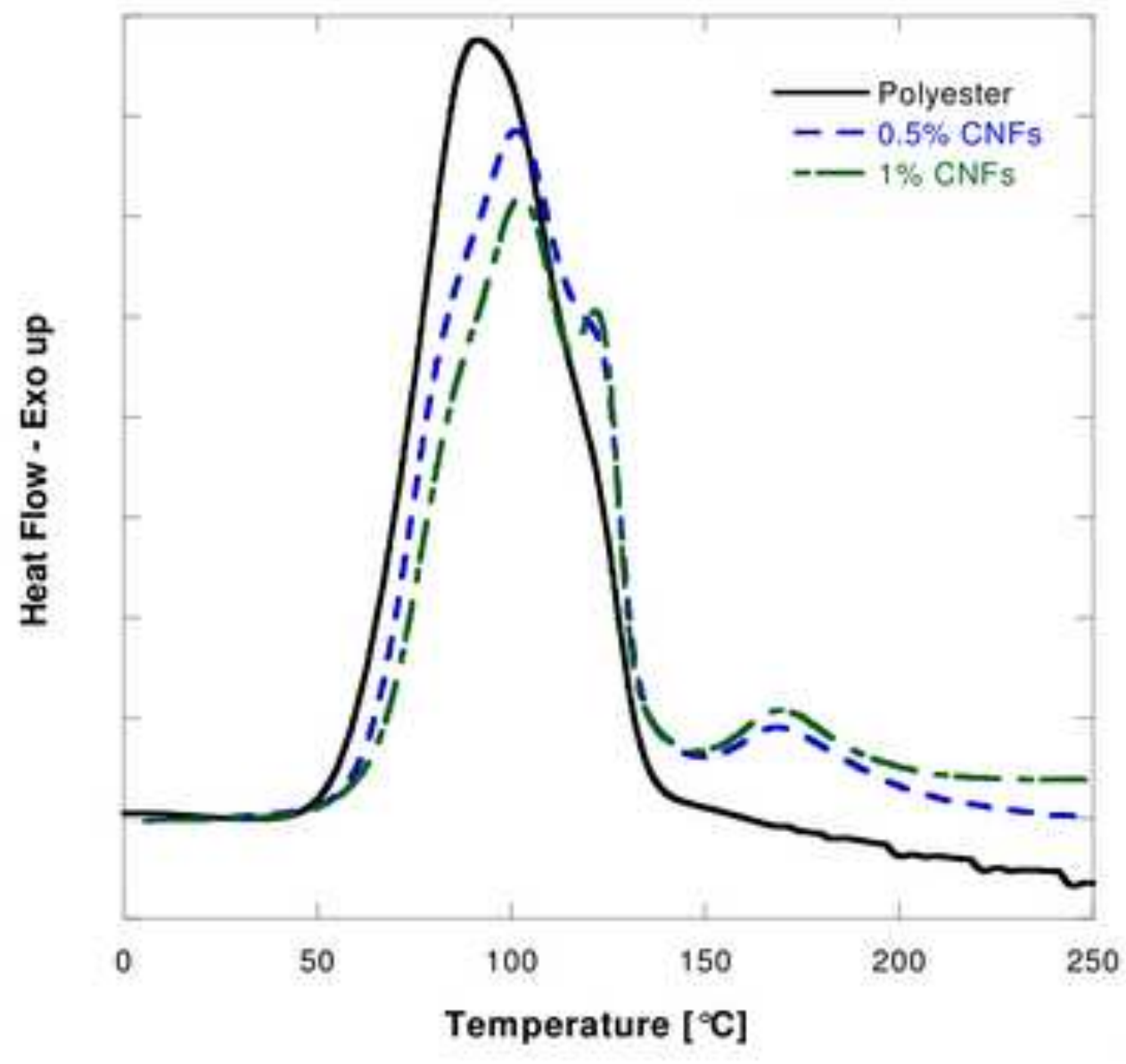

(a)

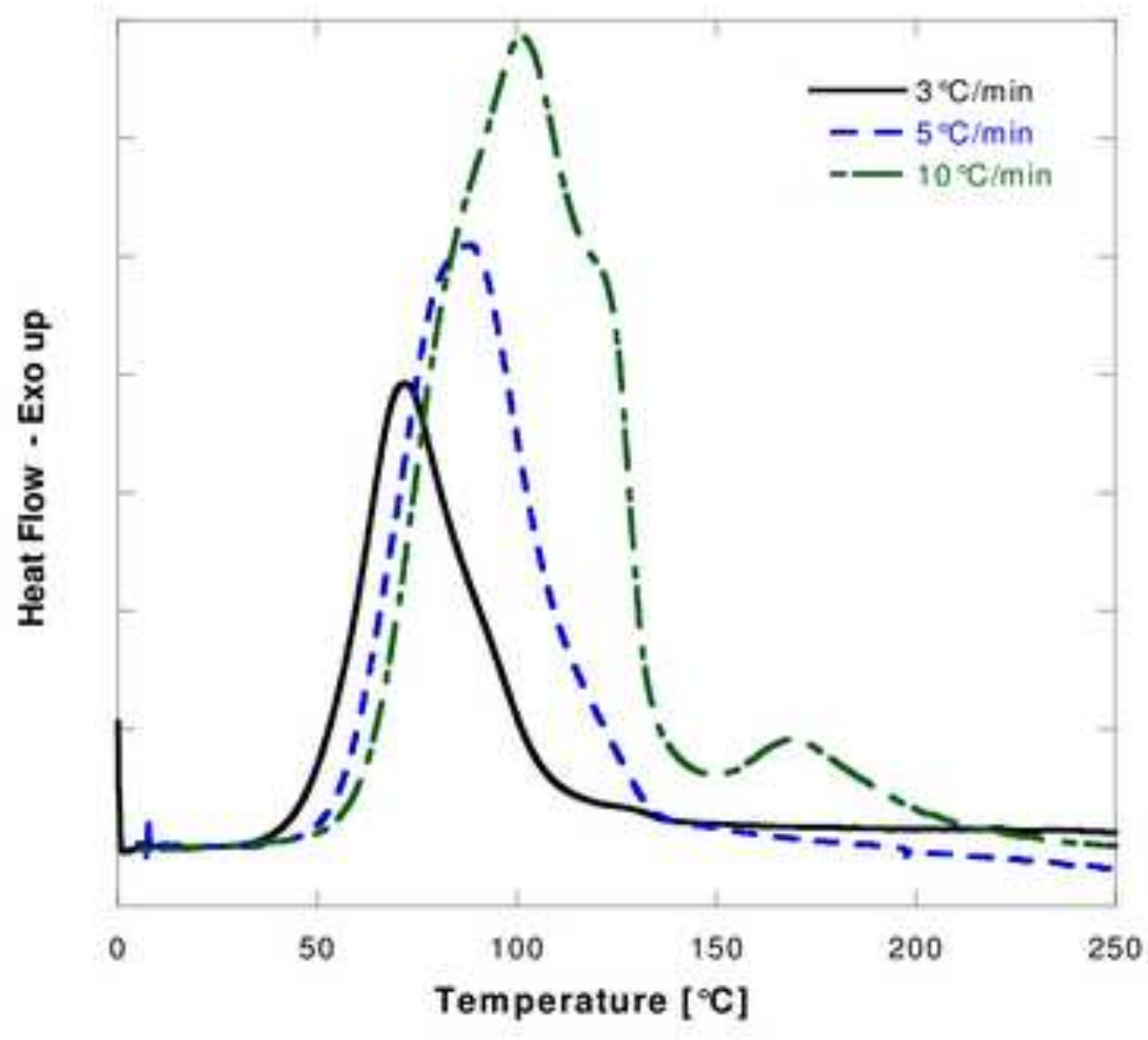

(b) 


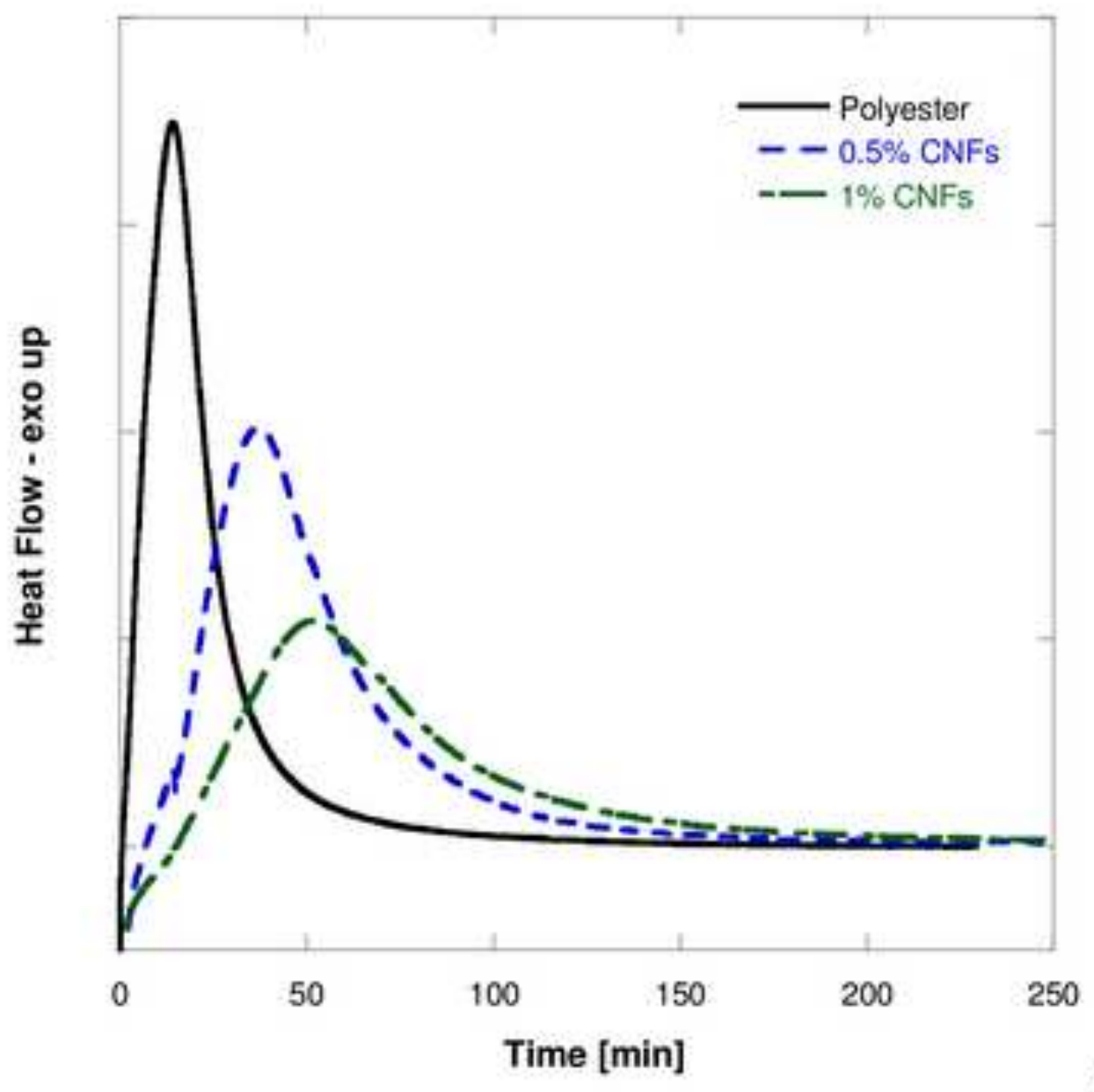

(a)

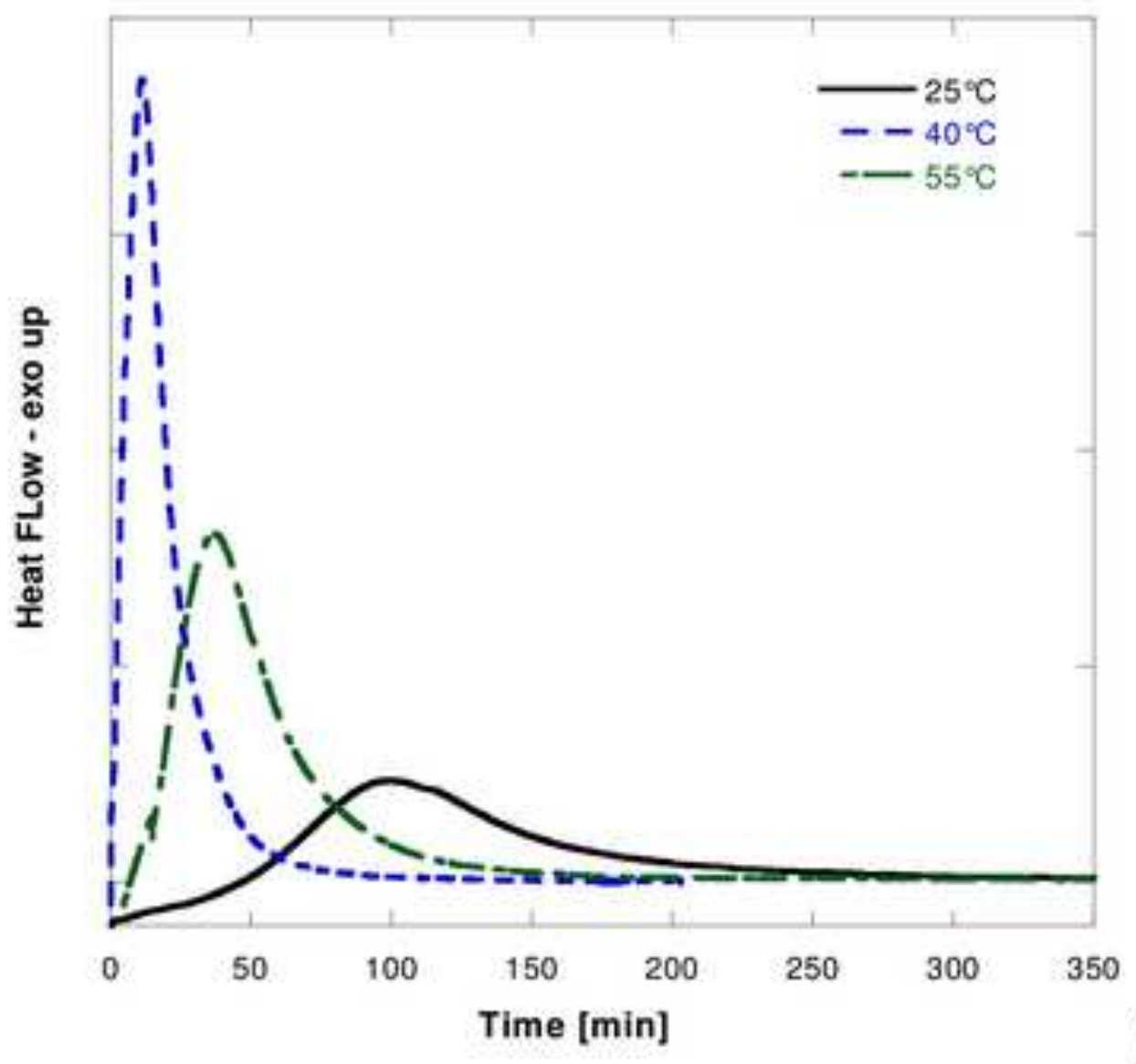

(b) 


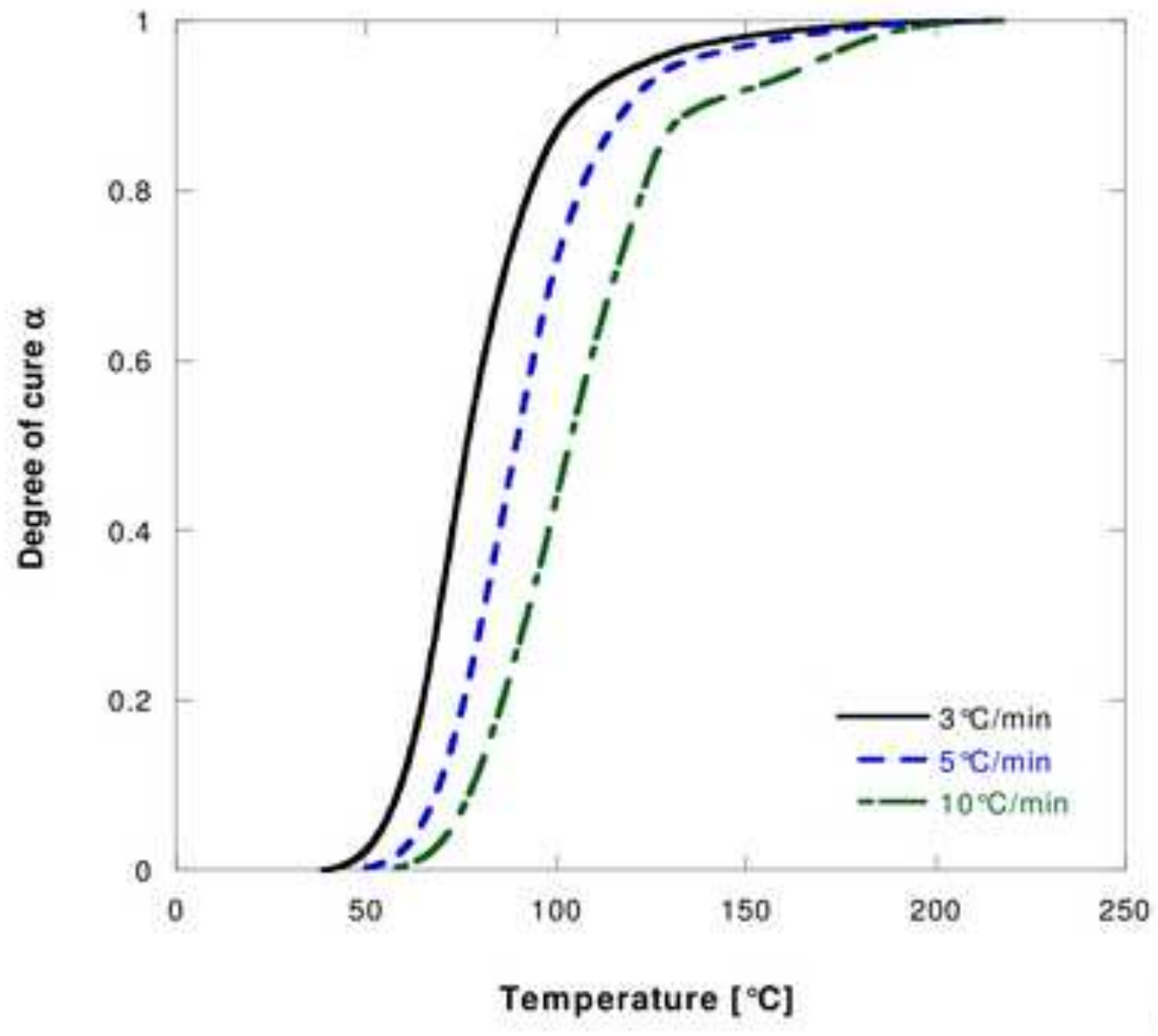

(a)

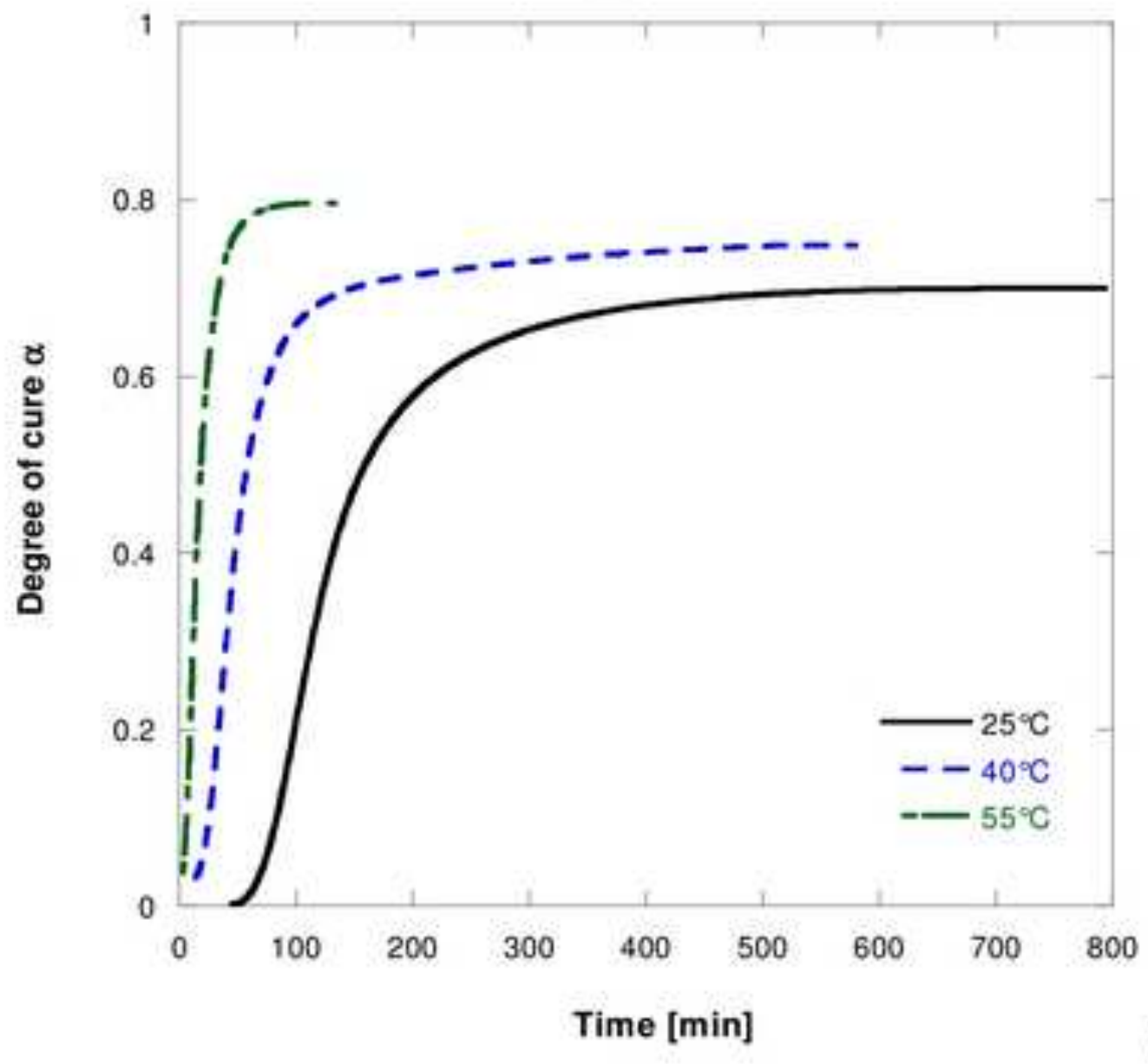

(b) 


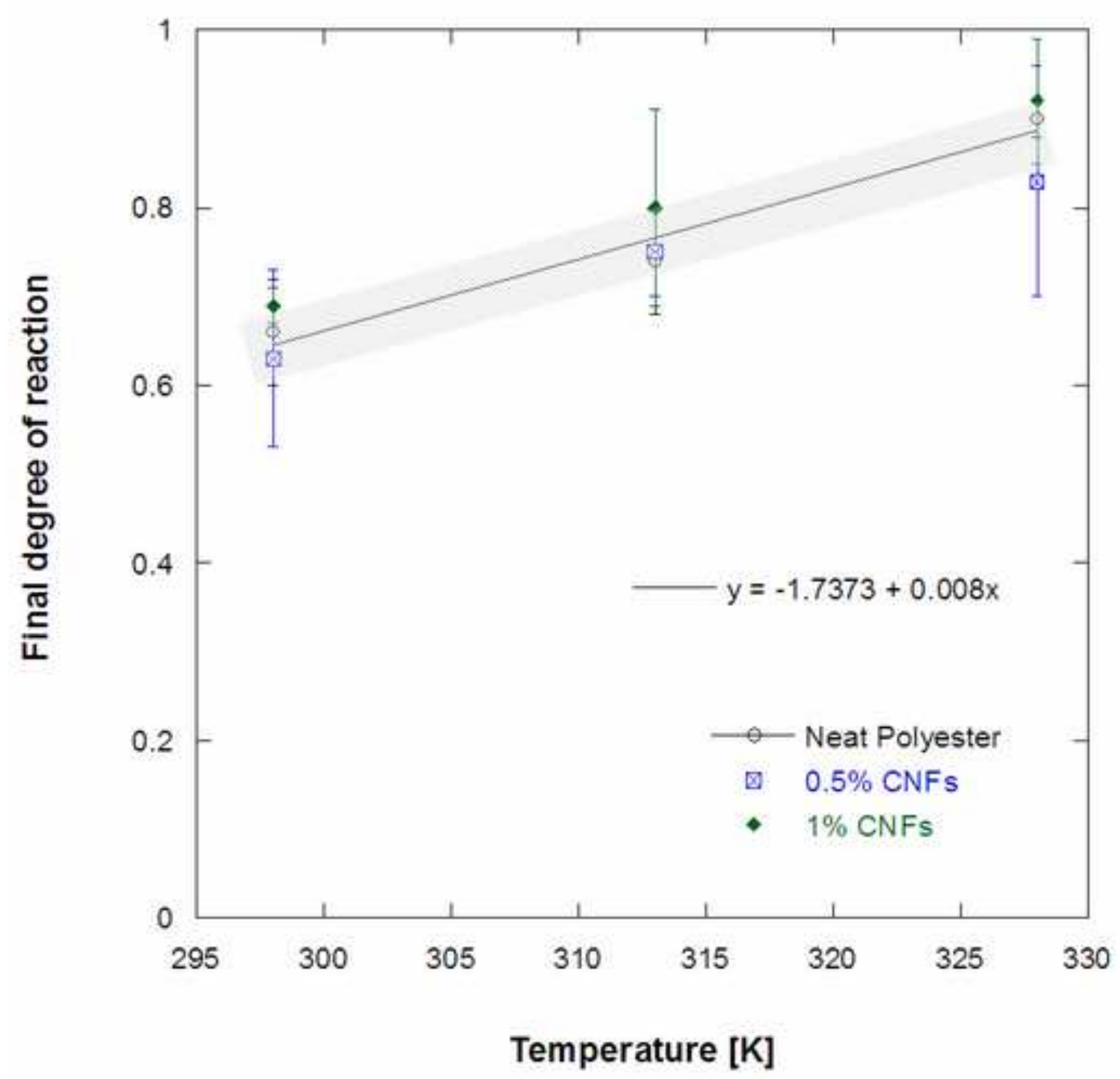

ACCEPTED MANUSCRIPT

Temperature [K] 
ACCEPTED MANUSCRIPT

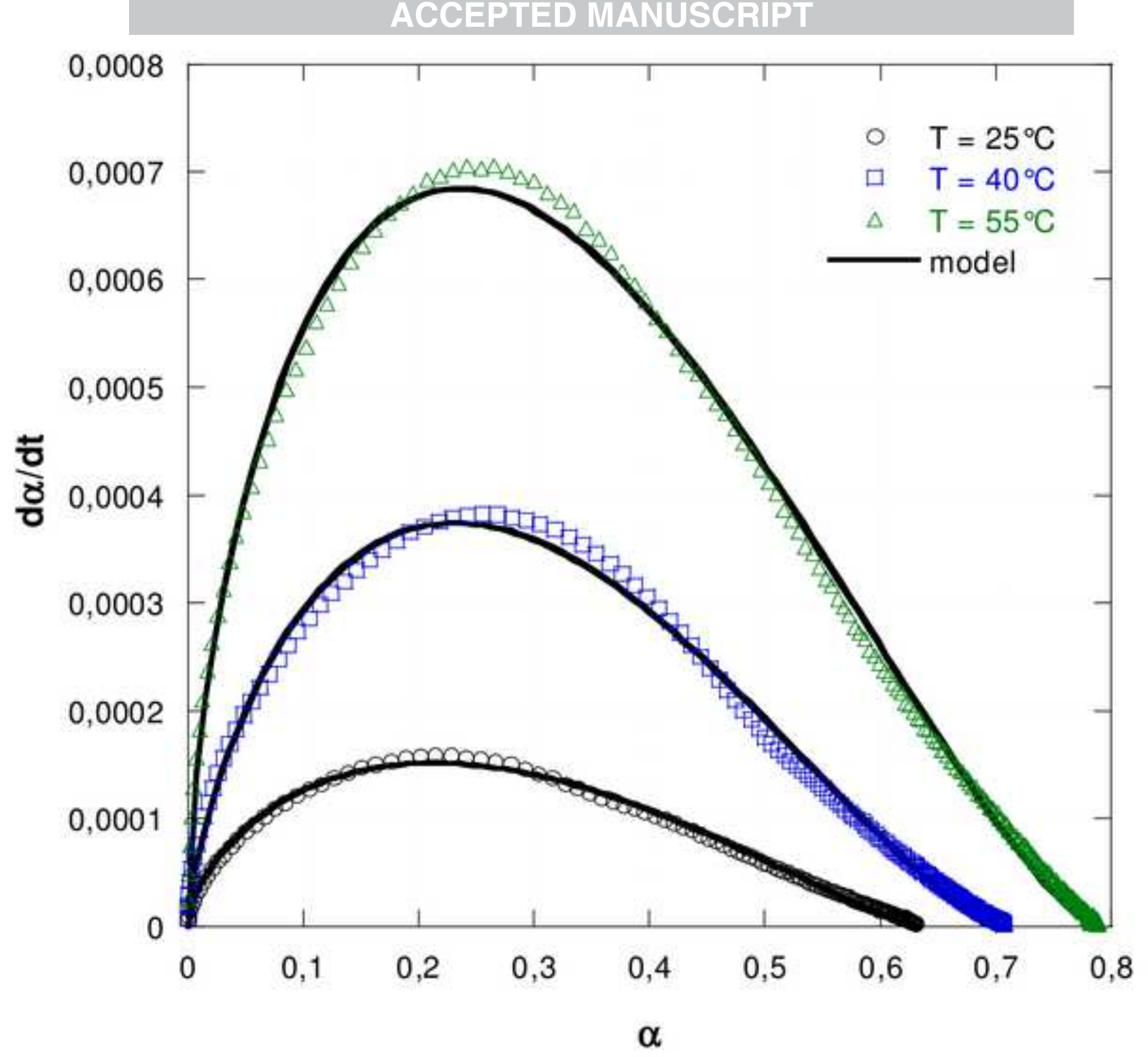

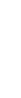


ACCEPTED MANUSCRIPT

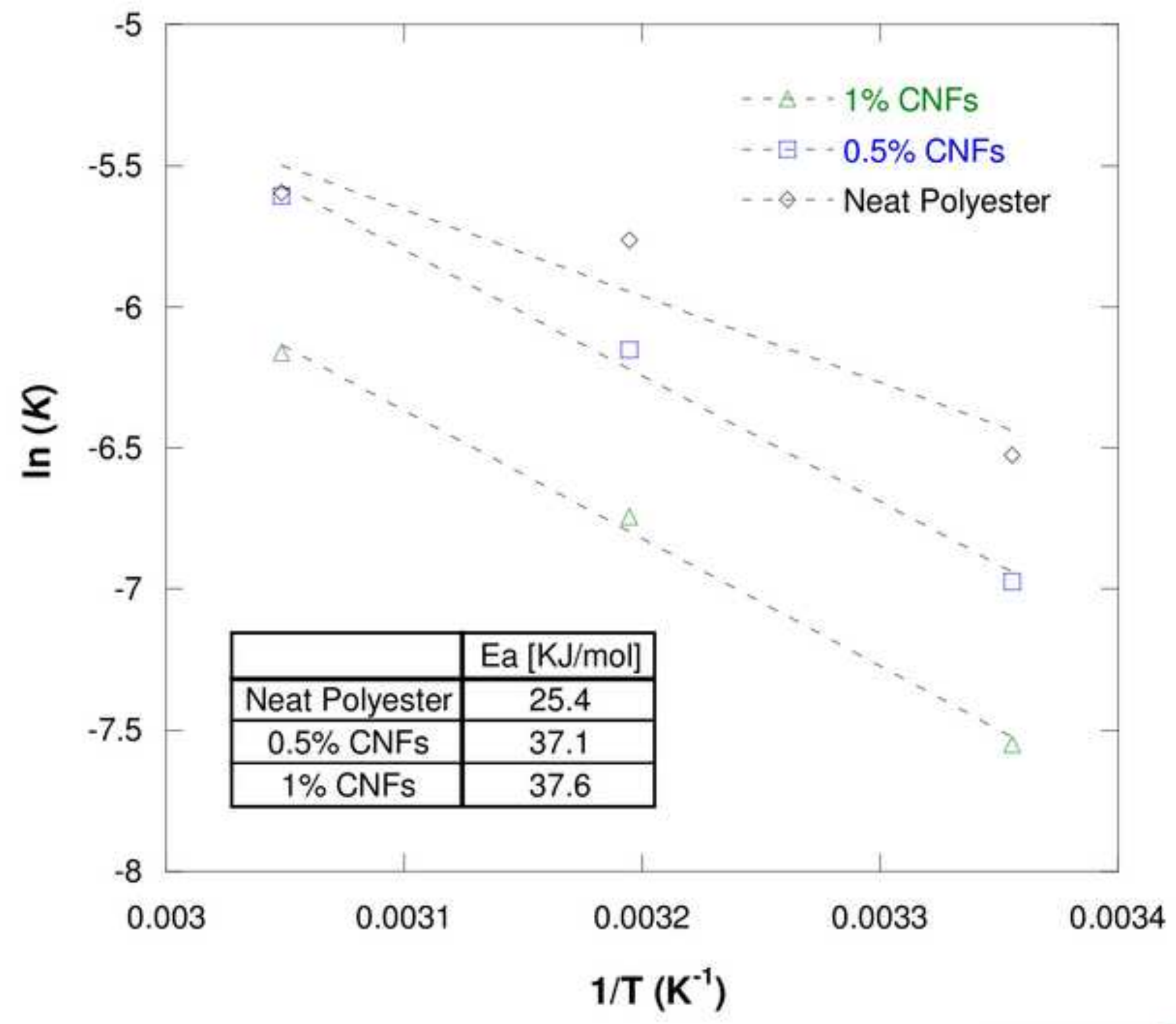




\section{ACCEPTED MANUSCRIPT}

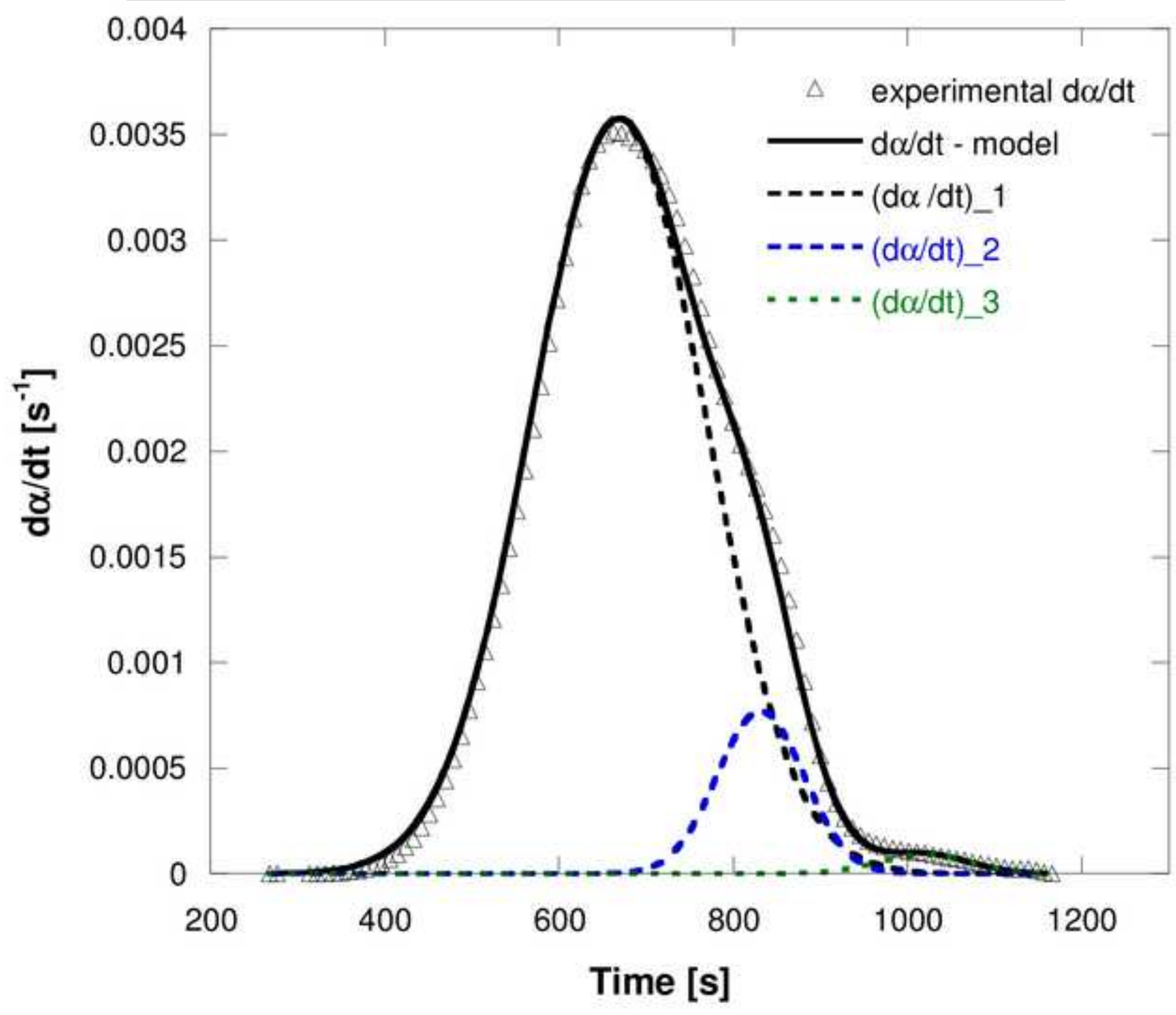




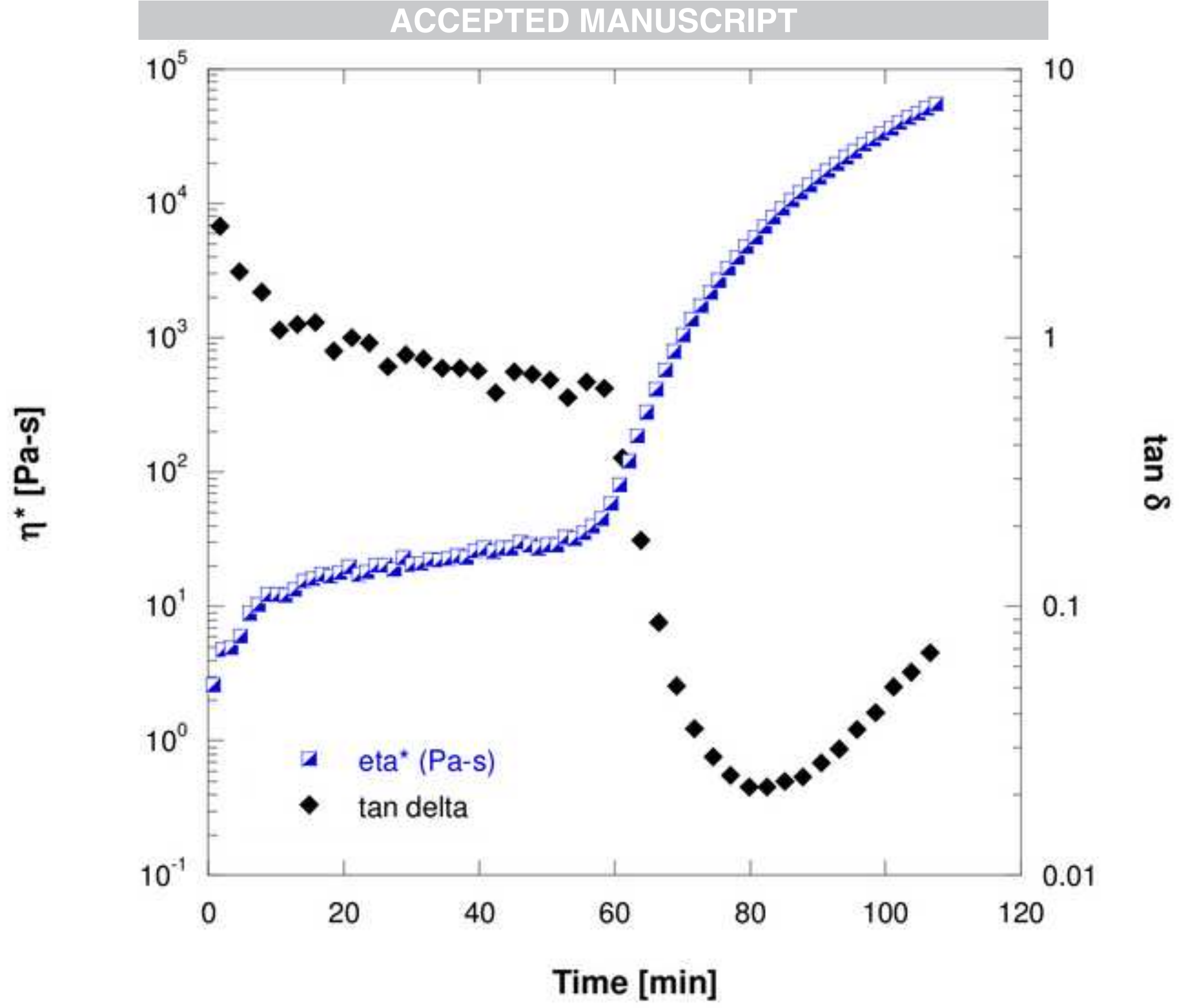




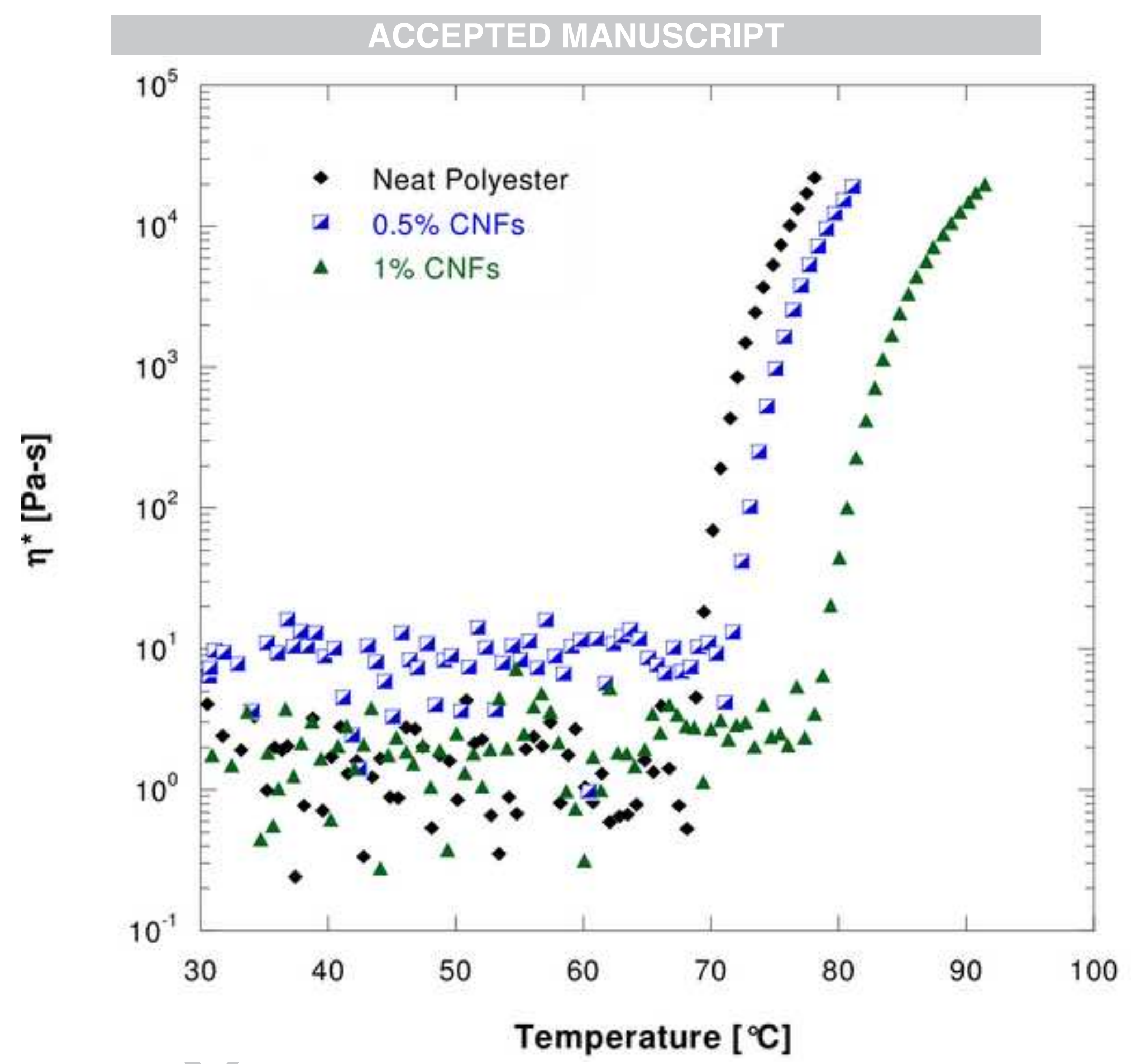



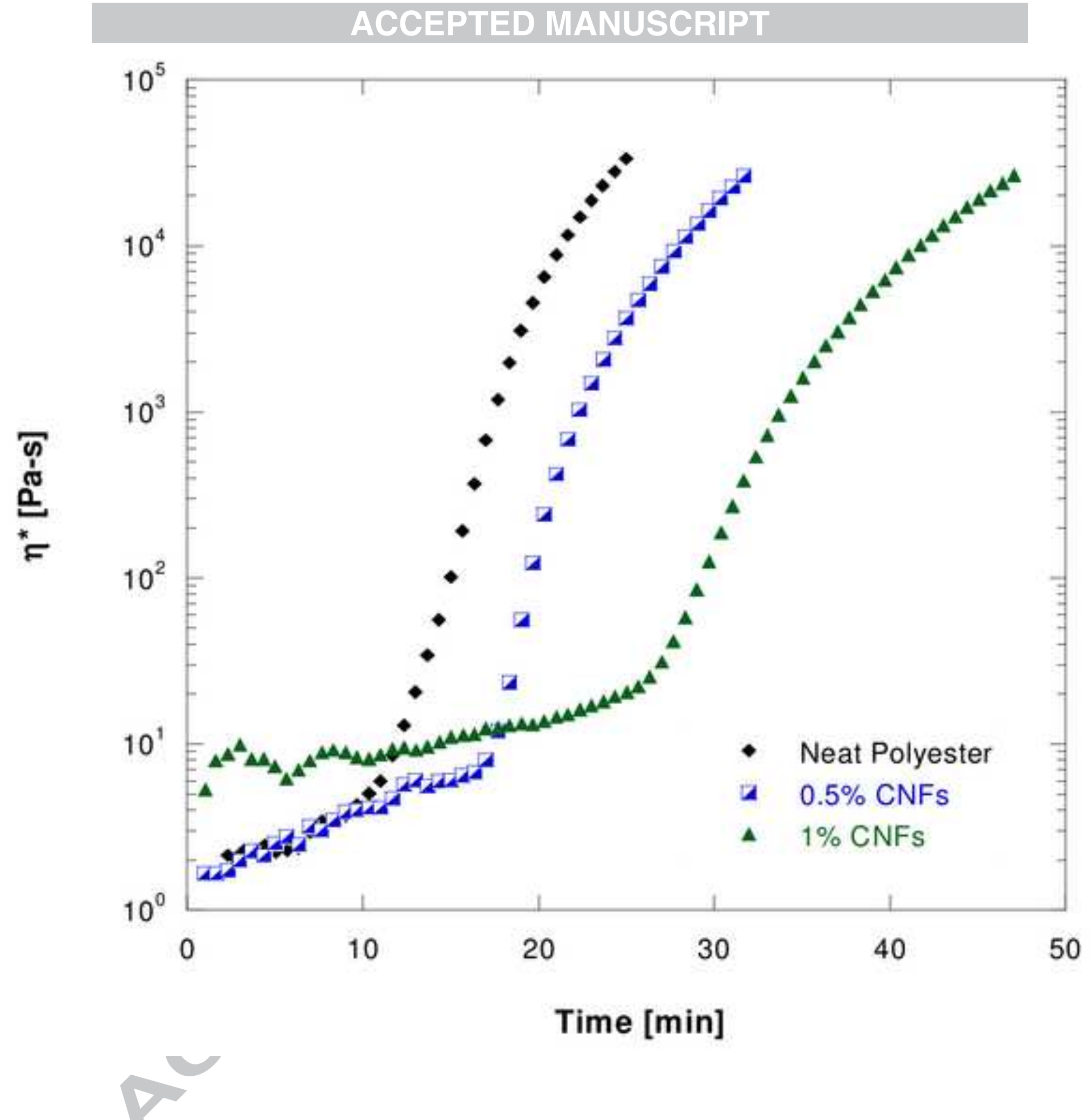

Time [min] 


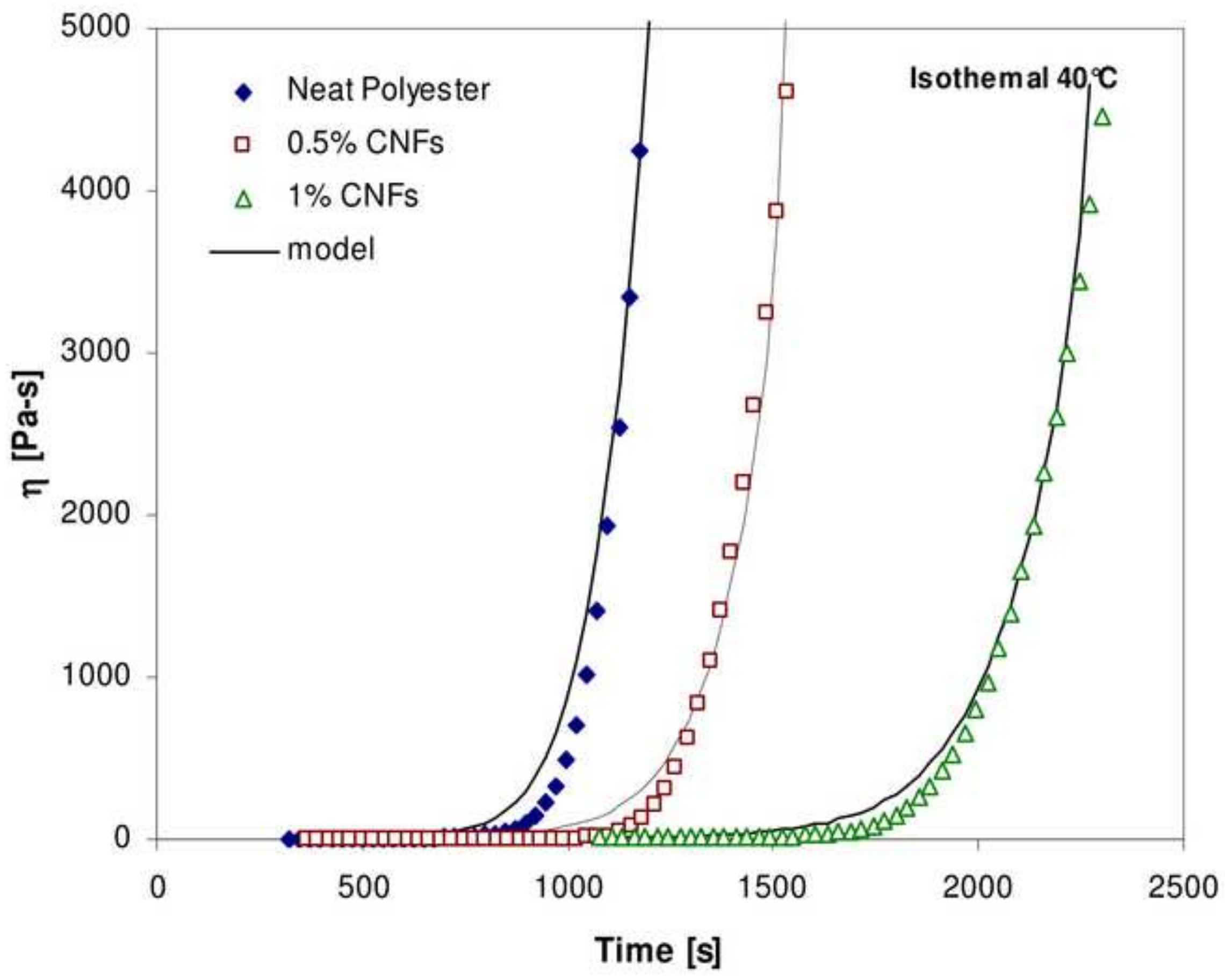

